\title{
Environmental fate and effects assessment of human pharmaceuticals: lessons learnt from regulatory data
}

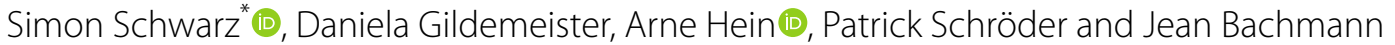

\begin{abstract}
Human pharmaceuticals are extensively studied and assessed before marketing approval. Since 2006, this also includes an assessment of environmental risks. In the European Union, this is based on the guideline on the environmental risk assessment of medicinal products for human use (EMEA/CHMP/SWP/4447/00 corr 2), which is currently under revision. For Germany, the German Environment Agency (UBA) is tasked with the evaluation of environmental risks of human pharmaceuticals. Applicants seeking approval of medicinal products need to submit fate and effect data, in case predicted environmental concentrations (PECs) exceed $10 \mathrm{ng} / \mathrm{L}$ in surface waters, or the substance is of specific concern through its mode of action or physico-chemical characteristics.

Over the last decade, this regulatory work resulted in an internal agency database containing effect data on approximately 300 active pharmaceutical ingredients (APIs). A considerable part of this data is currently not publicly available due to property rights held by the respective applicants. The database was evaluated to draw conclusions on how the current assessment approach may be improved.

The evaluation of aquatic effect data shows considerable variation in ecotoxic effect concentrations, but supports the current use of $10 \mathrm{ng} / \mathrm{L}$ as PEC action limit. For endocrine-active substances and antibiotics, a clear sensitivity profile was observed, which allows a more targeted assessment in the future. The conclusions drawn from terrestrial effect data are less clear, as the database itself is biased because information is only available for substances with high sorption. Further adaptations of the terrestrial assessment strategy, including action triggers, appear necessary. Fate data show a high persistence of many APIs: approximately $43 \%$ of all APIs are classified as very persistent; $12 \%$ of these show $\mathrm{DT}_{50}$ values in a range where abiotic or biotic degradation is not expected.

Overall, the evaluation has shown that improvements of the current guideline are possible.
\end{abstract}

Keywords: Environmental risk assessment, Human pharmaceuticals, Aquatic ecotoxicity, Terrestrial ecotoxicity, Trigger values, Persistence

\section{Highlights}

- Ca. 300 effect datasets of human pharmaceuticals evaluated

- Aquatic effect data support PEC action limit of $10 \mathrm{ng} / \mathrm{L}$

*Correspondence: simon.schwarz@uba.de

German Environment Agency (UBA), Woerlitzer Platz 1,

06844 Dessau-Rosslau, Germany
- Ca. $50 \%$ of human pharmaceuticals are persistent

- Terrestrial risk assessment needs to be improved.

\section{Introduction \\ Pharmaceuticals as environmental contaminants}

Pharmaceutical residues are widely recognised as contaminants in the environment [1-3]. Various active pharmaceutical ingredients (APIs) applied in human or 
veterinary medicine are frequently found in the environment [4]. Many active ingredients reach surface waters because they are not or only partly removed in sewage treatment [5], while others enter soils via the dispersal of sewage sludge [6]. Some examples have also shown that pharmaceuticals can lead to adverse effects in non-target organisms (e.g. $[7,8])$. European legislation has recognised the problem of pharmaceuticals in the environment and consequently Article 8(3) of Directive 2001/83/EC demands the assessment of environmental risks in the authorisation process of human medicinal products [9]. For the European Union, the "Guideline on the environmental risk assessment of medicinal products for human use" [10] describes the current requirement of an environmental risk assessment (ERA) for human pharmaceuticals. It is further supported by a questions and answers document [11], which provides clarification on several points left unclear in the guideline. Environmental issues concerning pharmaceuticals are still of great interest in the EU, however, the outcome of the environmental risk assessment is not part of the benefit-risk assessment in the authorisation procedure for human pharmaceuticals.

In March 2019, the European commission published a "European Union Strategic Approach to Pharmaceuticals in the Environment" [12]. This approach proposes a variety of actions to improve the knowledge on the environmental impact of pharmaceutical substances and to better manage them. The revision of the current guideline [10] is one of the possibilities to improve the quality and consistency of ERA of human pharmaceuticals.

\section{Regulatory evaluation of the environmental risk of human medicinal products}

In the current guideline of the European Medicines Agency (EMA) the evaluation is a tiered process [10]. In a first step (Phase I), active substances are screened to determine if assessment of persistence, bioaccumulation and toxicity (PBT) is necessary or if exposure is high enough to necessitate further assessment of risk in the environment. Therefore, Phase I requires data on the octanol/water partitioning coefficient $\left(\log \mathrm{K}_{\text {ow }}\right)$ and the calculation of an initial predicted environmental concentration in surface water $\left(\mathrm{PEC}_{\mathrm{sw}}\right)$. The $\mathrm{PEC}_{\mathrm{sw}}$ is based on the maximum daily dose, the fraction of market penetration, the amount of wastewater produced per person and the dilution of wastewater in surface waters. If $\mathrm{PEC}_{\mathrm{sw}}$ in Phase I is greater than or equal to the action limit of $10 \mathrm{ng} / \mathrm{L}$, a more detailed environmental fate and effect assessment is required in Phase II. There is an exception for substances that may exert adverse effects at concentrations lower than $10 \mathrm{ng} / \mathrm{L}$, like, e.g. potential endocrine disruptors [11]. These substances require Phase II assessment irrespective of the calculated $\mathrm{PEC}_{\mathrm{sw}}$. Furthermore, substances with $\log \mathrm{K}_{\mathrm{ow}}$ exceeding 4.5 need to enter a full PBT assessment, regardless of whether or not a Phase II risk assessment is needed.

The Phase II environmental fate and effects analysis again consists of two tiers. Tier A requires information on physico-chemical characteristics, environmental fate (studies on adsorption-desorption, ready biodegradability, transformation in water-sediment systems) and aquatic ecotoxicity (algal growth inhibition, Daphnia reproduction, fish development, and activated sludge respiration inhibition). Toxicity to groundwater organisms is based on the toxicity to daphnids only. Effect concentrations taken from these studies are used to derive predicted-no-effectconcentrations (PNECs) by applying a safety factor of 10 . PECs are divided by the respective PNEC value (surface water, groundwater) to form a risk quotient (RQ). In the following cases, a substance needs to enter an extended fate and effects analysis in Phase II Tier B:

- If the calculated risk quotient is greater than one, the PEC needs to be refined as much as possible, by using fate and metabolism data.

- If the substance shows high adsorption to sewage sludge (organic carbon normalised adsorption coefficient $\left(\mathrm{K}_{\mathrm{oc}}\right)>10,000 \mathrm{~L} / \mathrm{kg}$ or $\left.\mathrm{K}_{\mathrm{d}}>3,700 \mathrm{~L} / \mathrm{kg}\right)$ and is not readily biodegradable, terrestrial fate and effect studies are required. These include studies on aerobic and anaerobic transformation in soil, nitrogen transformation of soil microorganisms, seedling emergence and growth of terrestrial plants, acute toxicity to earthworms and reproduction of collembolans.

- If the substance is not readily biodegradable and shows a significant shift to the sediment in the water sediment study, toxicity to sediment dwelling organisms must be investigated.

- If the $\log \mathrm{K}_{\mathrm{ow}}$ is larger than 3 , bioconcentration needs to be tested.

Currently, the guideline is under revision [13]. A draft guideline has been published in 2018 [14] and was open for comments until June 2019. Besides major structural changes, there are several proposed changes in the ERA procedure itself. The draft guidance strictly follows the requirements of Directive 2001/83/EC as amended [9], in requiring an ERA for every new application. The draft guideline includes strategies for a tailored risk assessment of antibiotics and endocrine-active substances. For antibiotics, this includes testing of two species of cyanobacteria and one species of green algae, while testing of fish is no longer required. Furthermore, the definition of endocrine-active substances is broadened to not only include sexual endocrine disrupting compounds, but all active substances that may affect development or reproduction via steroid hormone pathways. 
Besides this, the assessment of secondary poisoning has been implemented for substances with a bioconcentration factor $\mathrm{BCF}>100 \mathrm{~L} / \mathrm{kg}$. The previously mandatory test on transformation in aquatic sediment systems [15] for substances not meeting the criterion readily biodegradable was removed from Phase II Tier A. Instead, a test on sediment toxicity is now mandatory for all substances which enter Phase II-Tier A [16-19]. Groundwater risk assessment has been changed to be based on the effect concentration of the most sensitive aquatic taxon, and the PNEC is calculated using an additional safety factor of 10. Finally, the action trigger for soil assessment has been changed from a trigger solely based on $K_{o c}$ to one based on both $K_{o c}$ and the use of the substance, expressed as the resulting PEC. Moreover, the currently required acute earthworm toxicity test [20] is replaced with an earthworm reproduction test [21]. [13]

\section{Evaluation of regulatory data}

Within the European Union, the EMA is responsible for the scientific evaluation of centralised marketing authorisation applications for pharmaceuticals. Most new, innovative medicines are evaluated by EMA while most generic medicines are assessed and authorised at national (mutual recognition and decentralised procedures) level in the EU [22]. The data requirements and standards governing the authorisation of medicines are the same in the EU, irrespective of the authorisation route. Marketing authorisation applicants are responsible for providing a dossier with an environmental risk assessment and the respective studies, which is then assessed for quality and correctness by regulatory authorities. These assessments are performed by national competent authorities of the respective member states. In Germany, the German Environment Agency (UBA) is tasked with the evaluation of environmental risk assessments of pharmaceuticals. This allows UBA to evaluate a large number of studies and extract the most important information for further analysis. Hence, this opportunity is used to explore the available information more closely, with the aim to help make informed changes in the new guideline. Topics of special interest are:

- Analysis of existent aquatic effect data to see whether the current action limit $\left(\mathrm{PEC}_{\mathrm{sw}}=10 \mathrm{ng} / \mathrm{L}\right)$, which was originally based on acute effect data [10], is appropriate for human pharmaceuticals, or should be revised.

- Comparison of sensitivity between the investigated aquatic taxa to identify if a tailored risk assessment is possible for certain substance groups.

- Analysis of the persistence of APIs.

- Examination of available terrestrial effect data and data on adsorption to sewage sludge to judge whether the current terrestrial risk assessment is appropriate.
The intention of the present study was to provide information on the current state of knowledge, which can be used for the revision of the guideline on human medicinal products, but also to identify further knowledge gaps. While previous publications have mainly reviewed and assessed data that is publicly available, e.g. in scientific literature or European public assessment reports [23-26], our evaluation is focussed on data available to regulatory authorities, originating from the authorisation process of human medicinal products. Therefore, our analysis provides an evaluation based on an extensive set of standardised and quality-checked data.

\section{Methods \\ Database}

The presented evaluation was based on the environmental data available to the UBA. The investigated effect and fate dataset came from studies submitted in the authorisation process of human medicinal products-in the following referred to as "regulatory data". In the majority of cases, those were GLP-compliant studies according to Organisation for Economic Co-operation and Development (OECD) test guidelines (TG). However, in several cases high-quality data from publicly available literature [27], which had previously been accepted during authorisation procedures, was also considered. No further literature search was performed. Thus, the analysis was based on regulatory accepted endpoints only. Data on human medicinal products for which the marketing authorisation in Germany was finalised after 2006 and before September $10^{\text {th }} 2019$ were considered. This includes centralised procedures (all EU-member states involved), mutual recognition, or decentralised procedures (several EU-member states involved) with Germany as reporting or concerned member state, and German national procedures (only Germany involved). Hence, the data should cover the vast majority of fate and effect data available to EU regulatory authorities. The database also included data on APIs that underwent the authorisation process but are currently no longer marketed in Germany.

All presented data passed quality checks in accordance to Moermond et al. [28]. Data from studies which violated the validity criteria of the respective OECD test guideline, or whose results were judged as implausible, and which were thus not used within their regulatory ERAs, were excluded from the analyses. Hence, the absence of effect data for an API can also be due to the fact that the submitted studies were not of sufficient quality to be accepted for this assessment.

Since a large portion of the data is based on confidential study reports from various pharmaceutical companies, the original data cannot be made publicly available. 
Several of the effect values, but nowhere near all of them, are published in Public assessment reports (PARs) for decentralised procedures or European public assessment reports (EPARs) for centralised procedures. These PARs and EPARs can be found on the website of the EMA [29] or head of medicines agencies [30] and were, e.g. evaluated by Gunnarsson et al. [26]. In the current publication, the evaluation of all confidential data available to European regulatory agencies allowed the use of a larger dataset, with the unfortunate restriction of not being able to transparently display the raw data.

The overall number of APIs for which environmental fate and effect data were available from regulatory evaluations at UBA and information on the different data subsets evaluated in this study are listed in Table 1. A list of the APIs included in the analysis, without the respective endpoints, is given in Additional file 1: Table S6.

\section{Grouping of APIs}

Specific substance groups were defined for the further evaluation of the data: medicines used to treat alimentary/metabolism disorders, antibiotics, antimycotics, antineoplastics (excluding those with endocrine mode of action), antiparasitics, (non-steroidal) anti-inflammatory drugs, antivirals, contrast agents, endocrine-active substances, neuroactives/analgesics/anaesthetics, vascular/ cardiac/blood therapeutic substances, and the category various. The grouping was in part inspired by the Anatomical Therapeutic Chemical (ATC) Classification System, but put more focus on organising APIs according to similar mode of action than grouping based on the target organ. The primary intention of the grouping was to have a means of structuring the results, while not being able to show substance names. More detailed information on the chosen grouping is given in Additional file 1: Table S1. In the available dataset, the defined group of EAS included oestrogen-, androgen- and progesterone-receptor agonists and antagonists, corticosteroids, steroid receptor modulators, as well as drugs influencing steroidogenesis.

\section{Aquatic effect studies-action limit}

Analysed aquatic effect data mainly consisted of tests performed according to study protocols published by the OECD:

- Freshwater algae and cyanobacteria growth inhibition test-OECD TG 201 [31]

- Daphnia magna reproduction test-OECD TG 211 [32]

- Fish early life stage toxicity test-OECD TG 210 [33].

In certain cases, especially for substances with an endocrine mode of action, data on fish full life cycle tests [34] or fish sexual development tests (OECD 234) [35] were available instead of early life stage tests. For antibiotics, "algae tests" were usually conducted with cyanobacteria, while for all other API the tests were conducted with green algae. For these tests, effect concentrations based on the endpoint growth were given preference over those based on yield. For daphnids and fish, depending on the study protocol, various endpoints could be assessed (e.g. mortality, growth, reproduction). The most sensitive of these endpoints was used for further analyses. All evaluations of aquatic toxicity were based on the lowest reliable no observed effect concentration (NOEC) or $10 \%$ effect concentration $\left(\mathrm{EC}_{10}\right)$ per substance and organism. If there was no effect at the highest tested concentration (e.g. in limit tests) the NOEC was set as greater than or equal to this concentration (= censored values, 40 of 309 cases). Because they still provide the useful information that no effect is to be expected at this concentration, these censored NOECs were retained in the dataset. The

Table 1 Overview on the number of APIs for which environmental fate and effect data were available from regulatory evaluations, and the datasets used for the different evaluations in this study

\begin{tabular}{llll}
\hline & Full dataset & $\begin{array}{l}\text { PEC action limit derivation } \\
\text { (excluding EAS and antiparasitics) }\end{array}$ & $\begin{array}{l}\text { Sensitivity analysis (excluding } \\
\text { APIs without definitive lowest } \\
\text { NOEC) }\end{array}$ \\
\hline Aquatic effect data on at least one taxon & 309 & 278 & 269 \\
aquatic effect data on all three taxa & 209 & 192 & 183 \\
Data from water-sediment simulation tests & 196 & - & - \\
Koc data available & 165 & - & - \\
Terrestrial effect data on at least one taxon & 47 & - & - \\
Terrestrial effect data on all three taxa & 33 & - & -
\end{tabular}

The full dataset included all data available to the UBA. The other two datasets were subsets of the full dataset. For PEC action limit derivation, endocrine-active substances (EAS) and antiparasitics were excluded. For sensitivity analysis, only APIs for which data on all three taxa was available, and for which a definitive NOEC (no censored value) was available for the most sensitive taxon, were used. The three relevant aquatic taxa were algae, crustaceans and fish, the three relevant terrestrial taxa were plants, annelids and collembolans 
collected aquatic effect concentrations and their respective PNECs were used to assess the current action limit for the tiered risk assessment. The basic idea of an action limit is that this is a concentration, below which effects of APIs are very unlikely to occur. Only substances with PECs higher than the trigger value need to enter further assessment. For some substance groups of APIs this approach is not feasible. Endocrine-active substances and antiparasitics are considered as highly toxic substances, for which a proposed action limit should not apply [14]. PNECs of these types of compounds could be lower than the action limit. Because of this, two different datasets were used. To provide a general scientific overview, the full dataset included effect data on all available APIs. In contrast, the adjusted dataset excluded all effect data on EAS and antiparasitics, to include only APIs for which the PEC action limit applies.

Analyses always based on the lowest available NOEC/ $\mathrm{EC}_{10}$ per active ingredient. Hence, each API contributed only one single effect concentration to the dataset used for action limit evaluation. A distribution function was fitted to the datapoints, comparable to the approach used in species sensitivity distributions (e.g. [36]). APIs, for which only censored data were available, were kept in the dataset. An exclusion of these APIs would predominantly result in the exclusion of high NOECs, which would lead to an artificial shift of the fitted distribution into a lower concentration range (discussed for species sensitivity distributions (SSDs) by [37]). However, this has to be kept in mind when interpreting the results. As base value for the action limit an overall " $5 \%$ NOEC" (the $5 \%$ quantile of the fitted distribution $=$ a concentration lower than $95 \%$ of all lowest NOECs/ $/ \mathrm{EC}_{10}$ ) and an overall "1\% NOEC" (the $1 \%$ quantile of the fitted distribution $=$ a concentration lower than $99 \%$ of all lowest NOECs/ $\mathrm{EC}_{10}$ ) of all effect data was defined. To derive a " $5 \%$ NOEC" and a "1\% NOEC" the available effect data were arranged in ascending order and a suitable distribution was fit to the data. Two different models were used for fitting. For the first one, the original data were $\log 10$ transformed. For the other one, the most suitable transformation was determined via the Box-Cox method [38]. In both cases normal distributions were fitted to the transformed dataset by maximum likelihood estimation. The $95 \%$ confidence intervals (CI) were calculated via parametric bootstrapping $(10,000$ iterations). Both models were visually inspected and their performance compared to each other.

All analyses were carried out using R 3.5.2 [39] and RStudio 1.1.463 [40], with the additional packages MASS [41], plotrix [42], fitdistrplus [43], car [44] and actuar [45]. The main results are based on distributions fitted via the function "fitdist". Additionally, a second calculation based on distributions fitted via the function "fitdistcens" (designed for censored data) [43], is provided in the supplement. $5 \%$ and $1 \%$ NOECs and their respective $95 \%$ confidence intervals were calculated using the "quantile"-function.

Results from octanol/water partitioning coefficient tests were used to compare lipophilicity to toxicity. All values were derived experimentally by the shake-flask method [46], the slow-stirring method [47] or comparable methods. The highest ion corrected $\log \mathrm{D}_{\text {ow }}$ measured in environmentally relevant $\mathrm{pH}$-range ( $\mathrm{pH} 5$ to 9) was used for analysis.

\section{Aquatic effect studies-comparison of sensitivity}

A comparison of sensitivity was done for APIs, for which data on all three taxa was available. In several cases the lowest NOEC originated from a study where no significant effects were observed at the highest tested concentration. Due to the lack of a definite endpoint, it could not be clearly determined which taxon was the most sensitive. Consequently, these cases were excluded from the dataset. For the evaluation, a distinction was made between cases where one taxon was clearly most sensitive (difference in NOEC between most and second-most sensitive taxon larger than 3.2-fold) and cases where there was only a low difference between most sensitive and second-most sensitive taxon (smaller than 3.2-fold). This was done to highlight cases where the conclusion on the most sensitive taxon may not only be based on the organismic reaction, but may also be influenced by the experimental design of NOEC/LOEC studies. The factor 3.2 was chosen because it is the maximum applied spacing factor between test concentrations in the OECD TG 201, 210 and 211.

\section{Persistence assessment}

In Phase II Tier A of the guideline, a stepwise approach is foreseen to assess the (bio-)degradability of active substances. In OECD TG 301 [48] or OECD TG 310 [49] substances may meet the criterion "readily biodegradable" (at least $60-70 \%$ ultimate biodegradation required in a time frame of $10 \mathrm{~d}$ depending on test conditions), which means that these APIs are assumed to rapidly and ultimately biodegrade under aerobic environmental conditions [50]. Therefore, no further testing is required. Substances which do not meet this criterion are assumed to reach the surface water in relevant amounts after passing the sewage treatment. Here, the substance distributes between water and sediment phase and may be transformed. Studies on biodegradation and transformation are part of the fate assessment of human pharmaceuticals in Phase II Tier $\mathrm{A}$, and covered by studies according to the following OECD study protocols: 
- Ready biodegradability-OECD TG 301 [48] or OECD TG 310 [49]

- The water-sediment simulation test-OECD TG 308 [15], for all substances not classified as readily biodegradable.

It is possible to waive the test on ready biodegradability, if a water sediment simulation test according to OECD TG 308 [15] is performed. This test provides information on the distribution of a substance between water and sediment, as well as the transformation or mineralisation of a substance. Degradation half-lives derived from water sediment-simulation studies are used for persistence classification [51] within the PBT assessment. Normally two different sediments under aerobic conditions are demanded for pharmaceuticals [11]. To give an overview of the persistence of APIs, the results of the ready biodegradability tests and the highest reported total system half-lives $\mathrm{DT}_{50}$ (water and sediment combined, primary degradation) per API from all OECD TG 308 studies were summarised. $\mathrm{DT}_{50}$ is defined as disappearance half-life of the parent compound (primary degradation) in the water-sediment simulation test. Data evaluation and kinetic analyses were conducted in accordance with FOCUS [52]. If the analysis in the study reports differed from the standards set under FOCUS, e.g. no single first order modelling was conducted, the data were recalculated. All reported values were extrapolated to $12{ }^{\circ} \mathrm{C}$, which reflects the mean temperature in European surface waters [51]. A disappearance half-life is used because non-extractable residues (NER) were considered as degraded in the derivation of the $\mathrm{DT}_{50}$ values. Until now there is no clear guidance how to consider NER in the regulations $[53,54]$. Persistence criteria were used in reference to the ECHA guideline [51], to provide a better description of the evaluated half-lives. Therefore, the total system half-lives were compared to the criteria for the sediment compartment [55].

\section{Terrestrial trigger evaluation and effect assessment}

The decision criteria of a terrestrial assessment are based on the adsorption value derived with batch equilibrium method:

- Adsorption/desorption-OECD TG 106 [56]

- Activated sludge sorption isotherm-OPPTS 835.1110 [57]

The distribution coefficient $\left(\mathrm{K}_{\mathrm{d}}\right)$ and the $\mathrm{K}_{\mathrm{oc}}$ provide information on the binding affinity of APIs to sewage sludge and soil. For human pharmaceuticals, determining adsorption values for 3 soils and 2 sludges is recommended [58]. APIs with high affinity for organic carbon may accumulate in sewage sludge, which in some countries is spread on soil.

To give an overview of the relationship between the fraction of substance partitioning to sewage sludge $\left(\mathrm{F}_{\mathrm{stp}}\right)$ and the respective $\mathrm{K}_{\mathrm{oc}}$ value, the $\mathrm{F}_{\text {stp }}$ values were calculated via SimpleTreat 4.0 [59]. Biodegradation was not considered in these calculations.

A terrestrial assessment is required if the highest $\mathrm{K}_{\mathrm{oc}}$ derived for sludge is $>10,000 \mathrm{~L} / \mathrm{kg}$ (or $\mathrm{K}_{\mathrm{d}}>3700 \mathrm{~L} / \mathrm{kg}$ ). We screened the literature for API concentrations determined in sewage sludge to compare the $K_{o c}$ values of APIs to the recent trigger value. In a further evaluation we determined the number of cases, in which APIs were detected in sewage sludge although their $\mathrm{K}_{\mathrm{oc}}$ value was below the terrestrial trigger. For the literature screening, the Google Scholar search engine [60] was used with the following keywords: sewage sludge, pharmaceuticals, wastewater treatment, biosolids. Only recent studies from 2012 to 2019 with data from industrialised countries, with comparable pharmaceutical consumption and sewage treatment technology to the EU, were considered [61-68]. In the case of multiple detections of pharmaceuticals in different studies the maximum concentration was considered as worst-case assumption. The results were summarised in Additional file 1: Table S4. For the comparison, $\mathrm{K}_{\mathrm{oc}}$ values in sludge available from validated OECD TG 106 studies or high-quality literature references were used.

Knowledge on terrestrial effect data might be helpful to derive a trigger value for soil. Therefore, ecotoxicity data were collected and analysed. Terrestrial effect data are tested according to OECD study protocols:

- Earthworm acute toxicity test-OECD TG 207 [20]

- Terrestrial plant seedling emergence and seedling growth test-OECD TG 208 [69]

- Collembolan reproduction tests in soil-OECD TG $232[70]$.

In very rare cases data on earthworm reproduction tests-OECD TG 222 [21] were available. All evaluations on acute earthworm toxicity were based on the lowest derived $50 \%$ lethal concentration $\left(\mathrm{LC}_{50}\right)$, all evaluations on plants, collembolans and earthworm reproduction were long-term tests and thus based on the lowest reliable NOEC or $\mathrm{EC}_{10}$. As in the aquatic assessment, if there was no significant effect at the highest tested concentration (e.g. in limit tests), the NOEC was set to be "greater than or equal to" $(\geq)$ this concentration, or the $\mathrm{LC}_{50}$ was set to be greater than this concentration. 


\section{Results}

\section{Aquatic effect studies-action limit}

The database contains 309 APIs for which at least one reliable effect study was available. Reliable effect studies for all three organism groups were available for 209 APIs. Effect concentrations (NOECs/EC $C_{10}$ ) ranged from $1 \mathrm{pg} / \mathrm{L}$ to $3.2 \mathrm{~g} / \mathrm{L}$, illustrating the high variation in ecotoxicity of APIs. For 87 APIs the NOEC or $\mathrm{EC}_{10}$ was lower than $0.01 \mathrm{mg} / \mathrm{L}$, the threshold for a substance to be classified as "toxic" (T) in PBT assessment according to the REACH Regulation [51]. In particular, substances with endocrine mode of action showed high toxicity, with numerous NOECs below $1 \mu \mathrm{g} / \mathrm{L}$ and even below $0.1 \mu \mathrm{g} / \mathrm{L}$. However, several substances such as antibiotics, antineoplastics, anti-inflammatory drugs, antiparasitics and neuroactive substances, which do not target the endocrine system, also evoked effects in non-target organisms at concentrations below $1 \mu \mathrm{g} / \mathrm{L}$. In general, substances with high $\log \mathrm{D}_{\text {ow }}$ tended to have higher toxicity. However, there were several examples of APIs with $\operatorname{low} \log \mathrm{D}_{\mathrm{ow}}(<3)$ which still had NOECs lower than $1 \mu \mathrm{g} / \mathrm{L}$ (Additional file 1: Figure S1) (Fig. 1).

If endocrine-active substances and antiparasitics were excluded, 278 APIs remained for which at least one reliable $\mathrm{NOEC} / \mathrm{EC}_{10}$ was available. The calculated $5 \%$ and $1 \%$ NOECs varied, depending on whether the full or adjusted dataset was used, and which transformation was applied. Both investigated models produced a fairly good fit. However, the fit of the theoretical distribution based on the Box-Cox-transformed dataset was slightly better than that based on log10-transformed data. Using the Box-Cox transformation, the 5\% NOEC was $0.449 \mu \mathrm{g} / \mathrm{L}$ (CI: $0.228-0.894 \mu \mathrm{g} / \mathrm{L})$ and the $1 \%$ NOEC was $0.0315 \mu \mathrm{g} / \mathrm{L}$ (CI: $0.013-0.079 \mu \mathrm{g} / \mathrm{L})$. If distributions were fitted via the method for censored data, $5 \%$ and $1 \%$ NOECs were even lower than estimated with the standard method (Box-Cox: 5\% NOEC $=0.312 \mu \mathrm{g} / \mathrm{L}, \mathrm{CI}$ : $0.143-0.689 \mu \mathrm{g} / \mathrm{L} ; 1 \% \mathrm{NOEC}=0.016 \mu \mathrm{g} / \mathrm{L}, \mathrm{CI}: 0.005-$ $0.046 \mu \mathrm{g} / \mathrm{L})$. Additional information on model results is provided in Additional file 1: Table S2, model performance is shown in Additional file 1: Figures S3-S6.

\section{Aquatic effect studies-comparison of sensitivity}

For 209 APIs effect data on all three taxa were available. However, 26 APIs, where the lowest NOEC was a "greater than"-value, were excluded. Hence, a direct comparison was possible for 183 APIs. Overall, fish were most sensitive in 86 cases (large difference: 50,

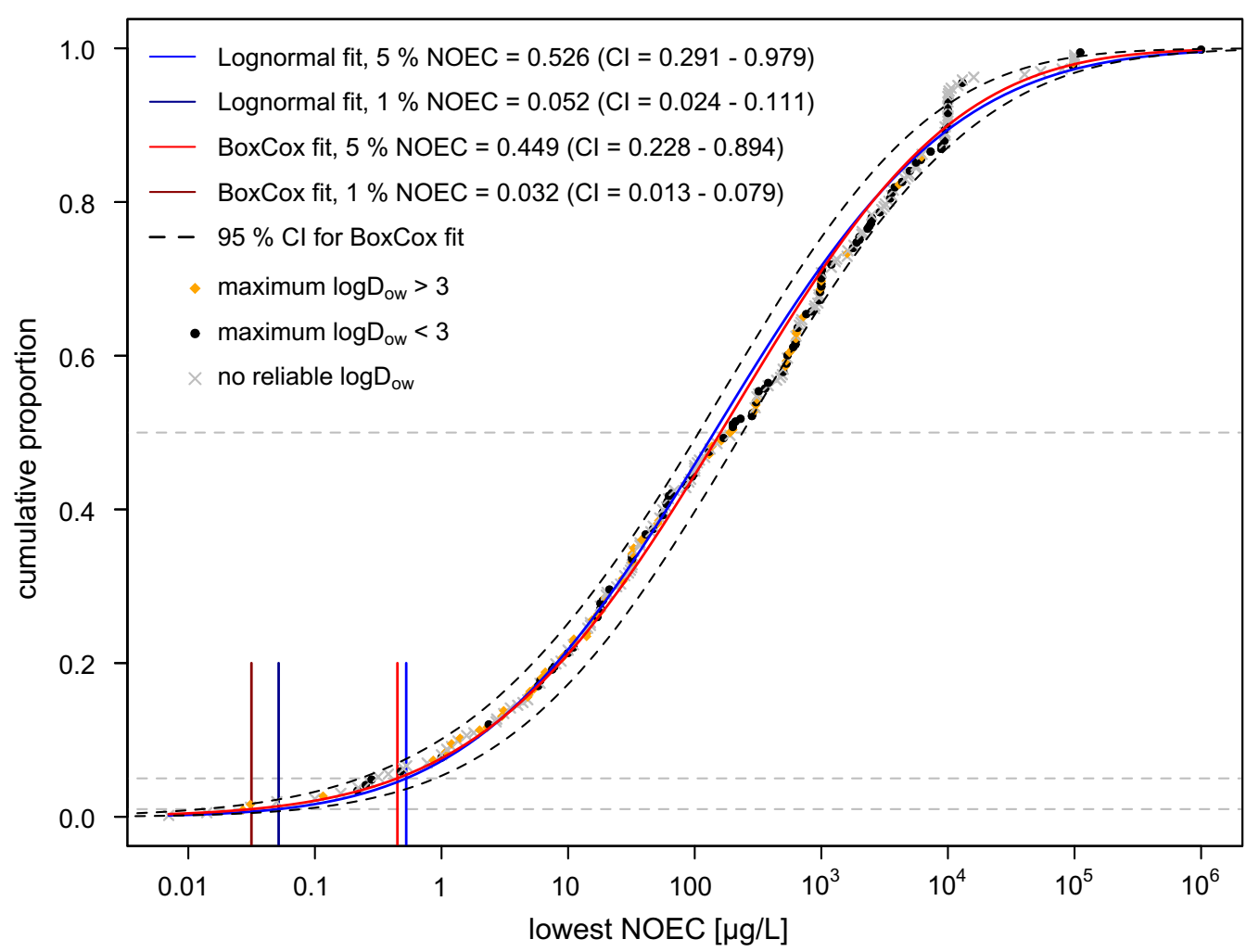

Fig. 1 The lowest available NOEC or $\mathrm{EC}_{10}$ available per API, arranged in ascending order. The plot is based on an adjusted dataset, where endocrine-active substances and antiparasitics were excluded (278 APIs). Further information on model metrics is given in Additional file 1: Table S2 
low difference: 36), green algae or cyanobacteria in 52 cases (large difference: 35, low difference: 17) and crustaceans in 42 cases (large difference: 19, low difference: 23). In 3 cases, daphnids and fish were equally sensitive (Fig. 2). There were certain pharmaceutical classes for which a distinct sensitivity profile could be observed. Cyanobacteria and green algae were highly sensitive to antibiotics-and were the most sensitive taxon for this substance group in all but one single case (15 of 16 cases). In the one diverging case, fish were slightly more sensitive than algae, but the NOECs were very close to each other. A similar trend was visible for antimycotics (in 3 of 4 cases algae were most sensitive). However, the total number of APIs in this group was too low to make a general conclusion. Furthermore, fish reacted very sensitively to endocrine-active substances (most sensitive in 14 of 15 cases). In one case, sensitivity of daphnids and fish was in a comparable range, albeit the NOEC for daphnids was slightly smaller. It is important to notice that most studies evaluating the effect of endocrine-active substances on fish were not fish early life stage tests, but rather fish sexual development or even fish full life cycle studies, as requested according to the guideline. For other pharmaceutical groups, such a clear sensitivity profile was not visible. For some, such as antiparasitics or contrast agents, a general conclusion was not possible since there was only one single data point for each of these groups.

\section{Persistence assessment}

Data on ready biodegradability were available for 248 APIs. Around 5\% (13 API) fulfilled the criteria of ready biodegradability. Data on biodegradation in watersediment systems according to OECD TG 308 were available for 196 APIs. The distribution of the half-lives (Fig. 3) showed that more than 50\% of APIs (101 of 196 APIs) were persistent (17 APIs) or very persistent (84 APIs) in the environment referring to the criteria given in the REACH guidance [51]. 23 APIs (12\%) had halflives above $1000 \mathrm{~d}$. It was not possible to relate long or short half-lives to specific groups of pharmaceuticals. All groups contained APIs with short and long

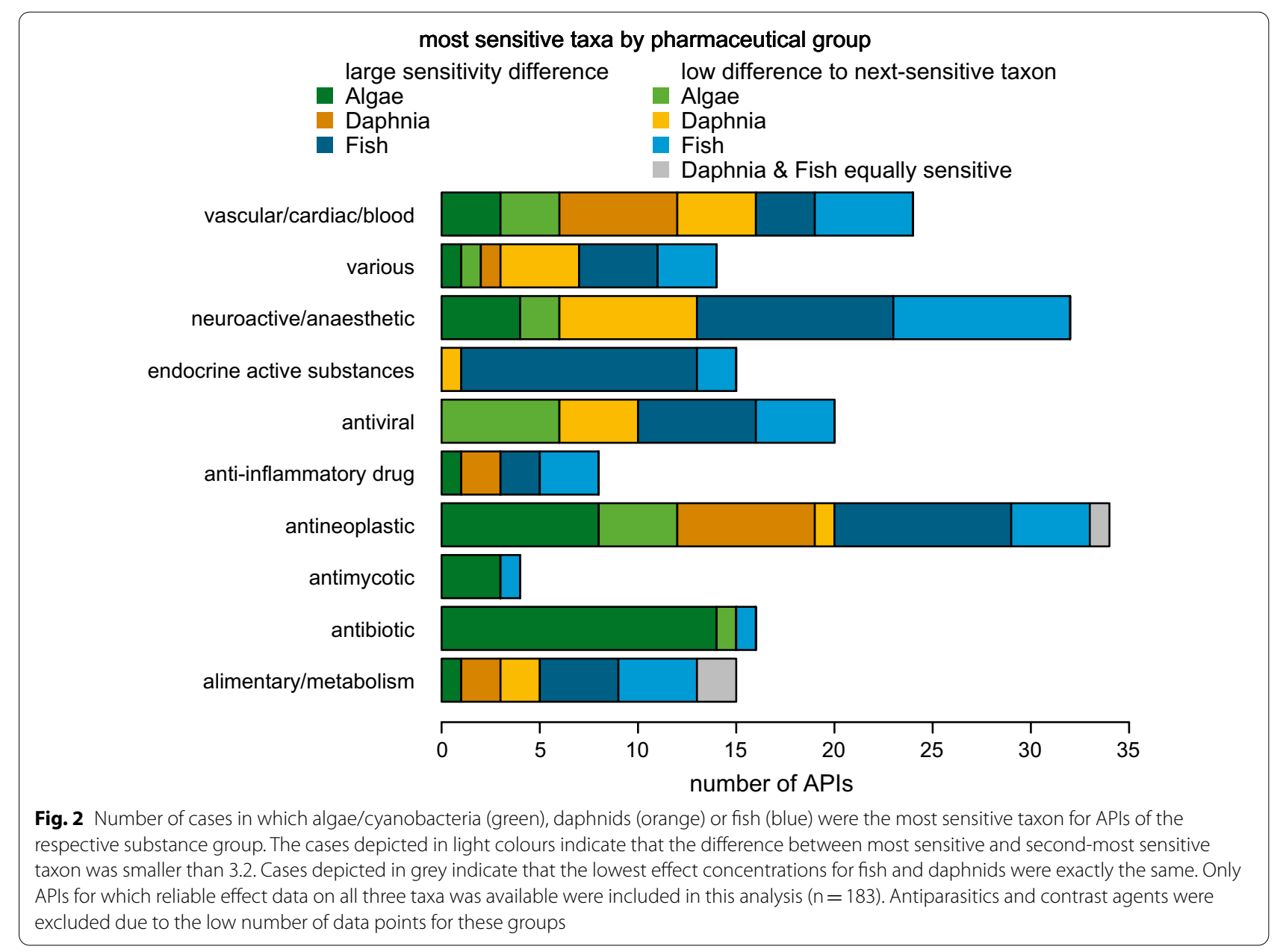


half-lives (see Additional file 1: Figure S11). This might be explained by the fact that chemical structures are not necessarily similar for substances within the same group.

To provide an overview of possible concerns for the environment, persistence and toxicity were compared for the persistent substances. For 70 of the APIs which were identified as environmentally toxic, $\mathrm{DT}_{50}$ values were available. Of these, 30 were persistent and toxic, of which 25 showed half-lives longer than $180 \mathrm{~d}$ (vP criterion is reached).

\section{Terrestrial trigger evaluation and effect assessment}

Data on sorption and desorption to sewage sludge were available for 165 APIs. In Fig. 4 the following paragraph the terms $\mathrm{K}_{\mathrm{oc}}$ or $\log \mathrm{K}_{\mathrm{oc}}$ are always used for values derived in sewage sludge.

For the majority of substances (125 out of 165$), \log \mathrm{K}_{\mathrm{oc}}$ was below the current trigger value for a soil assessment $\left(\log K_{o c}=4\right)$. Seven substances were highly mobile with $\log \mathrm{K}_{\mathrm{oc}}$ values below 1 , which signifies that there is a low elimination during sewage treatment. If there is also a low sorption to soils or sediments, such substances could easily leach into groundwater if no biotic or abiotic degradation occurs (high persistence). In reference to the 7 extremely mobile substances, one was highly persistent and one was persistent in view of data from OECD 308. For the other substances no data were available on biodegradation or they showed a moderate biodegradation. Around $20 \%$ of the substances with $\log \mathrm{K}_{\text {oc }}$ values below 2 were very persistent in reference to the ECHA criteria. $\operatorname{LogK} \mathrm{K}_{\text {oc }}$ for most of the substances ranged between 1.5 and 4.5, meaning that they all tend to adsorb to organic carbon during sewage treatment and in the environment, but could also be present in surface or groundwater depending on the overall use.

Calculations with SimpleTreat 4.0 (Table 2) showed the degree of sorption to sewage sludge for different $K_{o c}$ values considering no biodegradation (biodegradation rate constant $=0 \mathrm{~h}^{-1}$ ). This approach was justified by the outcome of the OECD TG 301 evaluation as only a minority of the substances were readily biodegradable. The fraction adsorbed to sludge (Fig. 4 and Table 2) showed that at a $\mathrm{K}_{\mathrm{oc}}$ value of $1000 \mathrm{~L} / \mathrm{kg}$, the sorption of the API to sewage sludge is clearly higher than $10 \%$ of the total amount present in the system. This is followed by a strong increase of sorption until a $\mathrm{K}_{\mathrm{oc}}$ value of $20,000 \mathrm{~L} / \mathrm{kg}$. For higher $\mathrm{K}_{\mathrm{oc}}$ values, the increase in sorption is less pronounced. At the current trigger value of

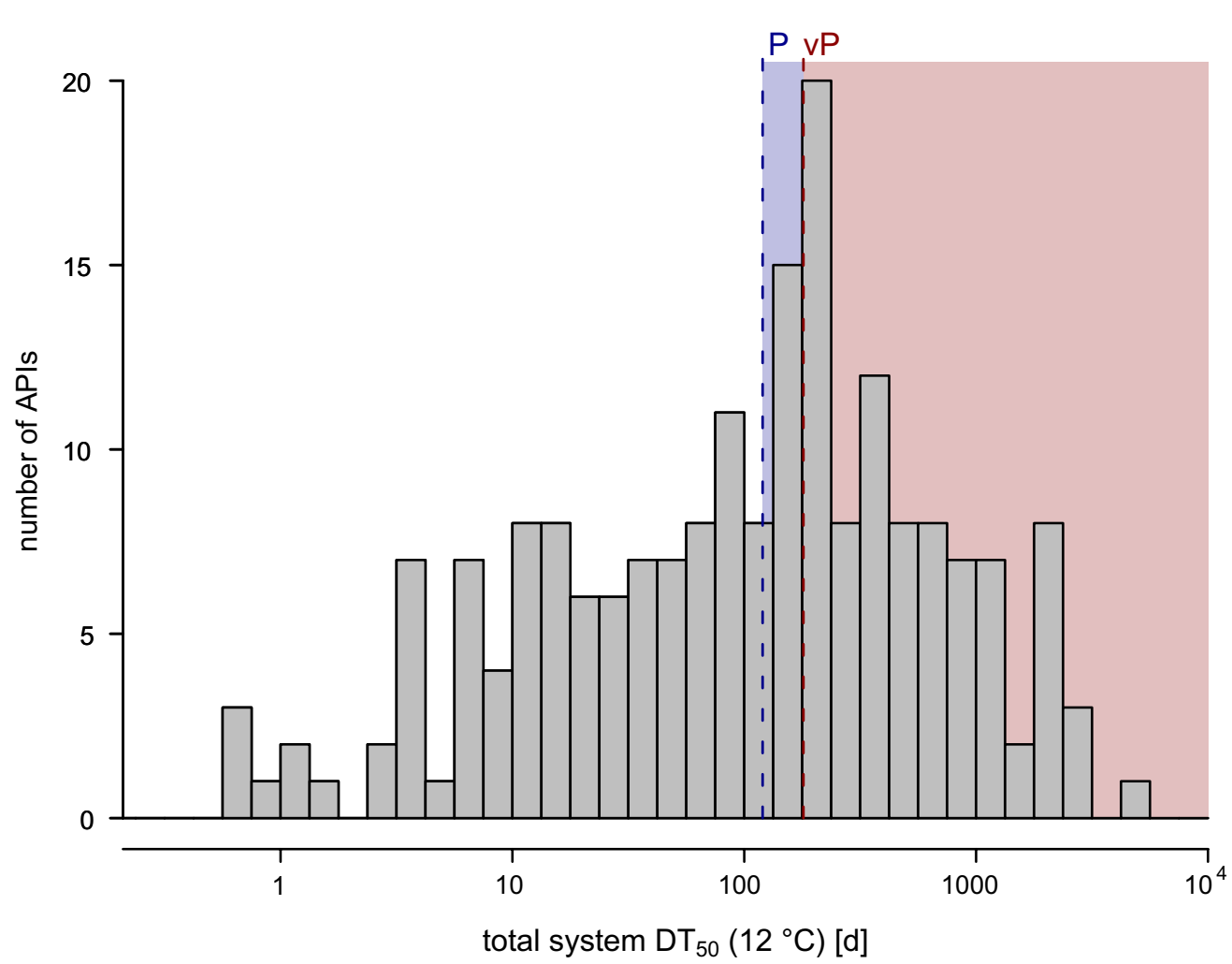

Fig. 3 Histogram of half-lives in the total system $\left(12^{\circ} \mathrm{C}\right)$ in water-sediment simulation tests of $196 \mathrm{APIs}$ (only parent compounds: active substances in original form). The persistence criteria [51] (at $120 \mathrm{~d}$ (P-persistent) and $180 \mathrm{~d}$ (vP-very persistent) are marked in blue and red 


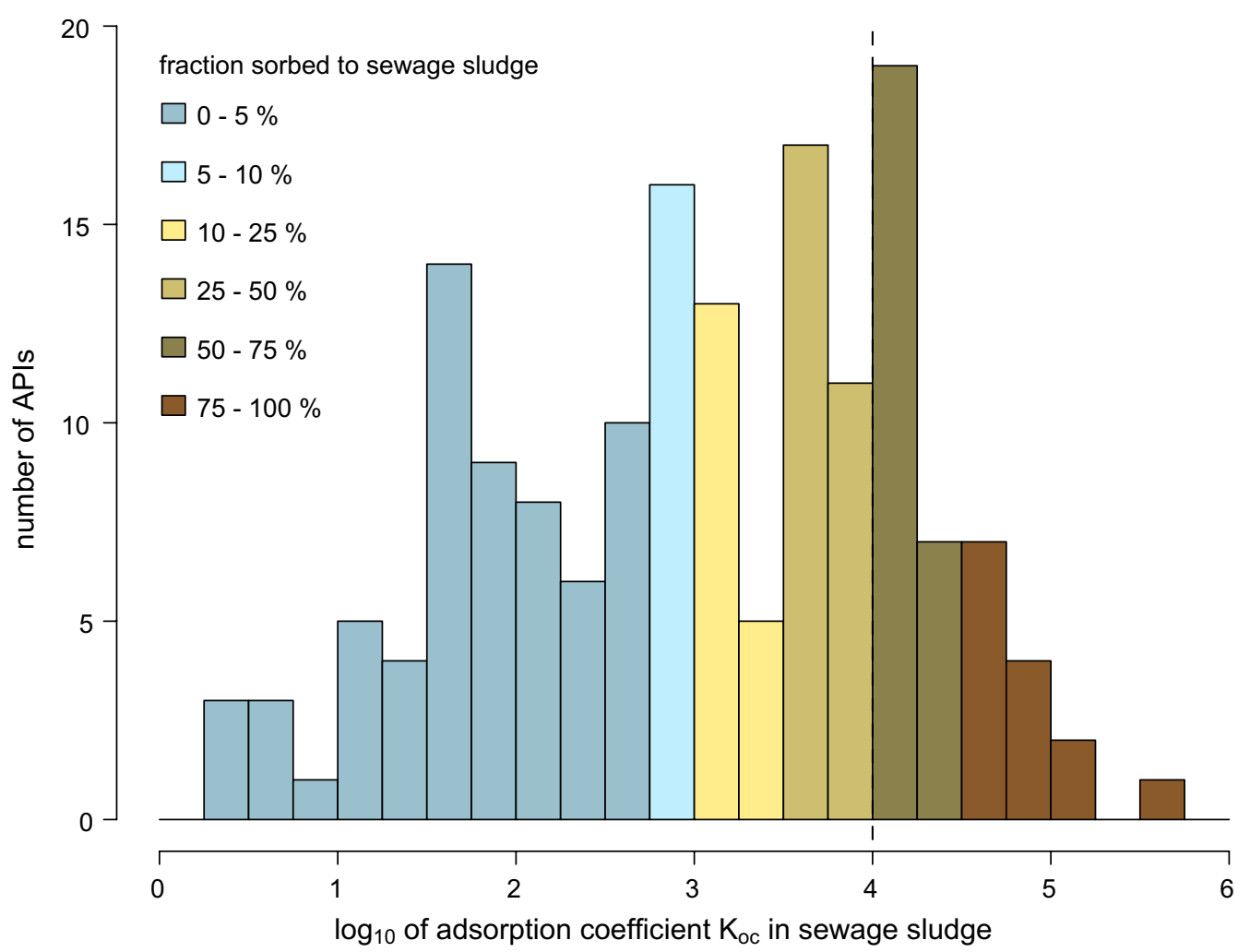

Fig. 4 Adsorption coefficients (log $\mathrm{K}_{o c}$ ) in sewage sludge of 165 APIs. The current trigger for terrestrial risk assessment, log $\mathrm{K}_{o c}=4$, is marked by a dashed line

Table 2 Influence of adsorption on emission to soil-based on modelling with SimpleTreat 4.0 (no biodegradation assumed)

\begin{tabular}{lll}
\hline $\mathrm{K}_{\text {oc }}[\mathbf{L ~ k g - 1 ]}$ & $\mathbf{l o g} \mathrm{K}_{\text {oc }}$ & $\mathbf{F}_{\text {stp }}{ }^{*}$ sludge [\%] \\
\hline 1000000 & 6.0 & 98.0 \\
100000 & 5.0 & 92.0 \\
50000 & 4.7 & 86.0 \\
20000 & 4.3 & 73.0 \\
10000 & 4.0 & 57.7 \\
7500 & 3.9 & 50.9 \\
5000 & 3.7 & 40.7 \\
2500 & 3.4 & 25.5 \\
2000 & 3.3 & 21.5 \\
1000 & 3.0 & 12.0 \\
500 & 2.7 & 6.0 \\
100 & 2.0 & 3.6 \\
\hline
\end{tabular}

${ }^{*} F_{\text {stp }}$ fraction sorbed to sewage sludge

$10,000 \mathrm{~L} / \mathrm{kg}$ approximately $60 \%$ of the substance is adsorbed to sewage sludge. However, for $\mathrm{K}_{\mathrm{oc}}$ values lower than $10,000 \mathrm{~L} / \mathrm{kg}$, sorption to sewage sludge is also substantial. For example, at a $\mathrm{K}_{\mathrm{oc}}$ value of $5000 \mathrm{~L} / \mathrm{kg}$, a fraction of approximately $40 \%$ of the API in the system is adsorbed to sludge.
A $\mathrm{PEC}_{\text {soil }}$ value depends on the degree of adsorption to sewage sludge and on the total amount of the substance present in wastewater $\left(\mathrm{E}_{\text {local }}=\right.$ local emission to the sewage treatment plant (STP)). This means that APIs with a moderate adsorption behaviour $\left(\mathrm{K}_{\mathrm{oc}}<10,000 \mathrm{~L} / \mathrm{kg}\right)$, but used in large amounts could have a higher $\mathrm{PEC}_{\text {soil }}$ than APIs with a $K_{o c}>10,000 \mathrm{~L} / \mathrm{kg}$ but lower usage. To investigate this relation, a literature screening was performed for concentrations of APIs determined in sewage sludge. In sewage sludge, 110 APIs were detected (see Additional file 1: Table S4). For only 25 of those substances, validated $\mathrm{K}_{\mathrm{oc}}$ values in sludge were available from environmental risk assessments. For the majority of the substances (22 of 25), $\mathrm{K}_{\mathrm{oc}}$ values for sludge were below the soil assessment trigger of 10,000 L/kg; for some substances even below $1000 \mathrm{~L} / \mathrm{kg}$. This indicates that risks for soils might be overlooked because there is a high influence of the use of a substance.

Terrestrial effect data were available for 47 human APIs (Fig. 5). For 33 of those, this included valid effect data on all three taxa relevant for ERA (plants, earthworms and collembolans). In all evaluated acute earthworm tests (42), the highest tested concentration did not result in a significant effect on mortality, and 


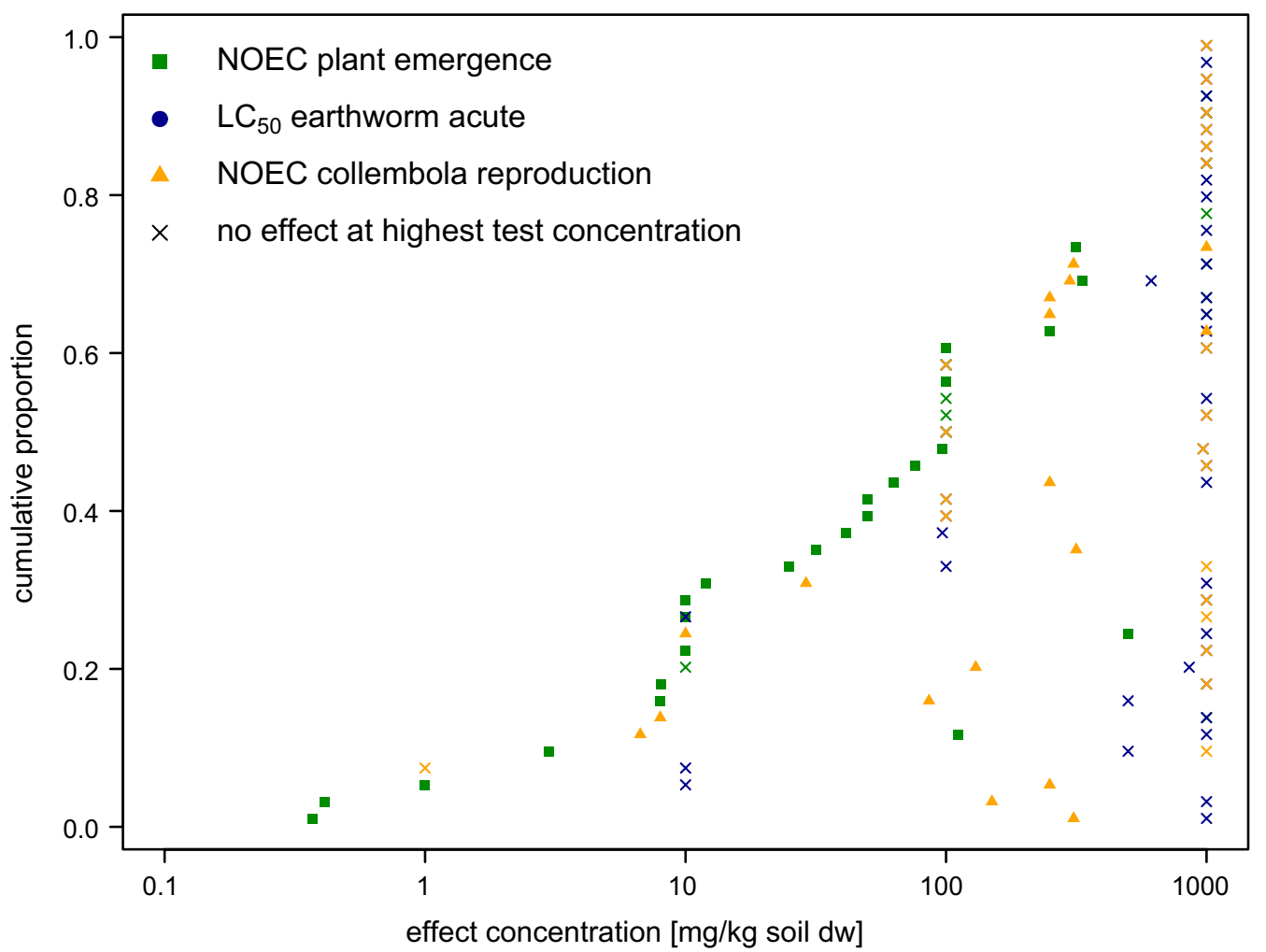

Fig. 5 Terrestrial NOECs and $\mathrm{LC}_{50} \mathrm{~S}$ for 47 human APIs, ordered by the lowest overall effect concentration per API. Different studies on the same API are displayed at the same height. For none of the investigated APIs, significant acute effects on earthworms were reported

consequently the resulting $\mathrm{LC}_{50}$ was higher than the tested concentration range. Plants and collembolans showed more sensitive NOEC values than the acute earthworm tests. Still, in 13 of 38 plant studies and 21 of 38 collembolan studies, no significant effect was observed at the highest tested concentration. Overall, 39 of 43 APIs, for which long-term terrestrial effect data were available, showed NOECs higher than $1 \mathrm{mg} / \mathrm{kg}$. For two APIs, NOECs were smaller $1 \mathrm{mg} / \mathrm{kg}$, for two others, NOECs were equal to $1 \mathrm{mg} / \mathrm{kg}$ (more detailed information is given in Additional file 1: Figure S9). As the data base was considerably smaller and suffered from a systematic bias (see discussion section) an analysis as conducted for the aquatic effect data to derive the 1\% and 5\% NOEC was not conducted for terrestrial data.

\section{Discussion}

One drawback of our evaluation is that the original database cannot be disclosed due to confidentiality issues. This has the disadvantage that the analyses cannot be fully retraced, and the database is not openly available. When comparing our database and the one used by Gunnarsson et al. [26] (detailed comparison of the databases is provided in supplementary information), it became clear that only a part of the data available to regulatory authorities is published in (European) public assessment reports and available for evaluations by others. This problem and the respective background were recently discussed by Oelkers, Floeter [71]. Future efforts should aim at improving the public availability of environmental data on pharmaceuticals in the EU.

\section{Aquatic effect studies-action limit}

The available aquatic effect data illustrate the wide range in ecotoxicity of APIs. While certain substances elicit effects in the $\mathrm{pg} / \mathrm{L}$ to $\mathrm{ng} / \mathrm{L}$ range, others do not cause effects even in the high $\mathrm{mg} / \mathrm{L}$ range. Substances influencing the hormonal system and antiparasitics can be considered to be the most potent pharmaceutical groups in general. Although the database for the latter group was very limited, other published data support this assessment [72]

The 5 and 1\% lowest NOECs (Fig. 1) and their resulting PNECs serve as a scientific basis to evaluate the currently existing PEC action limit of $0.01 \mu \mathrm{g} / \mathrm{L}$ for surface water. However, several factors have to be kept in mind when interpreting the data: 
1) The used dataset contained censored NOECs from tests that did not find a LOEC at all (e.g. limit tests). For SSDs, the benefits of including censored data were discussed [37]. While these data are not as informative as unbounded $\mathrm{EC}_{10}$ or NOEC values, they still provide useful information that no effect occurred at the highest tested concentration. Excluding these data would mean that mainly APIs with high effect concentrations are disregarded, with a shift of the overall distribution towards a lower concentration range. Including censored NOECs leads to some uncertainty in the fit, but is preferable to completely omitting relevant information from the analysis.

2) The analysis is based on a sample set of 278 APIs, in which some pharmaceutical groups are under- and others overrepresented. Full effect datasets of all three relevant taxa were available for 192 APIs. Both fitting models show that very low and very high values have considerable leverage on the calculated fit. The addition of further data on additional APIs, if these are in the low or high toxicity range, may influence the derived fit and resulting $5 \%$ and $1 \%$ quantiles. However, considering the large database, the overall estimation of the quantiles and their $95 \%$ confidence intervals should be sufficiently robust.

3) The calculated 5 or $1 \%$ NOECs mean that still 5 or $1 \%$ of all NOECs are below these values. A certain proportion of substances may always be missed when an action limit is based on these quantiles. For a regulatory guideline, it has to be decided to which degree harmful effects can be tolerated. For SSDs, the $5^{\text {th }}$ percentile of the derived distribution (HC5) is normally used as relevant effect concentration, though this practice can also be questioned from an ecological point of view [73]. A prospective risk assessment should achieve a high degree of protectiveness. Hence, it would be a valid option to derive the action limit from the $1 \%$ NOEC.

As intended in the guideline, variability and uncertainty should be addressed by using an assessment factor to calculate a PNEC. The PNEC is calculated by applying an assessment factor of 10 to the lowest NOEC or $\mathrm{EC}_{10}$ [10]. If the specific sensitive groups of substances, like endocrine-active substances and antiparasitics, are excluded, this results in $5 \%$ and $1 \%$ PNECs of $45 \mathrm{ng} / \mathrm{L}$ (CI: $22.8-89.8 \mathrm{ng} / \mathrm{L}$ ) and $3.2 \mathrm{ng} / \mathrm{L}$ (CI: $1.3-7.9 \mathrm{ng} / \mathrm{L}$ ), respectively. These values are in a close range to the current PEC action limit of $10 \mathrm{ng} / \mathrm{L}$. Furthermore, when looking at the original NOEC data, only one of 278 APIs (excluding endocrine-active substances and antiparasitics) had a NOEC below $10 \mathrm{ng} / \mathrm{L}$ and seven of the APIs, belonging to the groups of antineoplastics, neuroactives, anti-inflammatory drugs and vascular/cardiac/blood therapeutic substances, had a NOEC below $100 \mathrm{ng} / \mathrm{L}$ (with a corresponding PNEC of $10 \mathrm{ng} / \mathrm{L}$ ). This indicates that the
$10 \mathrm{ng} / \mathrm{L}$ action limit can be assumed to be protective with sufficient certainty in the majority of cases, which supports the approach of both the existing guideline [10] and the new guideline draft [14]. An increase of the PEC action limit would result in overlooking a larger portion of potentially relevant pharmaceuticals.

In general, the evaluation shows that pharmaceuticals with higher $\log \mathrm{D}_{\mathrm{ow}}$ tend to have lower effect concentrations (Additional file 1: Figure S1). It must be kept in mind that the ecotoxicity tests, on which the evaluations were based, were not necessarily conducted at the $\mathrm{pH}$ which results in the maximum $\log \mathrm{D}_{\mathrm{ow}}$ of the tested substance. This may be partly responsible for the observed variance of the correlation. However, the high variability also suggests that other factors besides lipophilicity influence ecotoxicity. Similar conclusions were drawn by Vestel et al. [74]. In view of such connections between lipophilicity and toxicity, Gunnarsson et al. [26] proposed the prioritisation of legacy pharmaceuticals based on consumption-based PEC and $\log \mathrm{D}_{\mathrm{ow}}$ : in the PEC range between 10 and $100 \mathrm{ng} / \mathrm{L}$, APIs with $\log \mathrm{D}_{\mathrm{ow}}>3$ would be considered high priority and APIs with $\log \mathrm{D}_{\mathrm{ow}}<3$ would be considered medium priority. On the other hand, our dataset featured several APIs with $\log \mathrm{D}_{\mathrm{ow}}<3$ and PNECs below $100 \mathrm{ng} / \mathrm{L}$, indicating that less lipophile substances can still have relevant effects. Furthermore, recent studies, e.g. Bittermann et al. [75], proposed that it is of limited usefulness to base toxicokinetic models for ionisable substances, e.g. most pharmaceuticals, on the partition coefficient in water and octanol. Instead, these models should rather utilise the membrane-water partition coefficient or liposome-water partition coefficient.

Considering this, triggering based on a combination of environmental concentration and $\log \mathrm{D}_{\text {ow }}$ of 3 is not suitable in a prospective risk assessment like the ERA for marketing authorisation. It may however be used as one of the variables when substances are prioritised for retrospective risk evaluation.

\section{Aquatic effect studies-comparison of sensitivity}

Several conclusions can be drawn from comparing effect concentrations between the three standard taxa used for aquatic toxicity testing (green algae/cyanobacteria, daphnids, and fish). Variation in sensitivity were very large for certain APIs, and reached up to a factor of $4 \times 10^{7}$ between the test species, for a single substance. Although fish were the most sensitive taxon for roughly $50 \%$ of APIs, algae and daphnids were also relevant in a considerable proportion of cases. This confirms the current procedure of investigating all three taxa in Phase II. However, for antibiotics and endocrine-active substances a specifically sensitive taxon was clearly observed (Fig. 2). For these groups of substances, a tailored testing strategy should be used. 
For antibiotics, fish were hardly ever the most sensitive species (except for one case, where the sensitivity of cyanobacteria and fish was in a very similar range). Thus, further testing of fish species for antibiotic ERA is unnecessary and not in line with the 3R strategy to reduce vertebrate testing [76]. Rather, testing of ecotoxicity should focus on algae and cyanobacteria. This is in line with the pharmacological modes of action of APIs belonging to this group, and confirms previous analyses comparing sensitivity of different organisms groups to antibiotics [77]. These drugs act, e.g. on bacterial cell wall synthesis or bacterial protein biosynthesis. Drug targets are therefore likely to be present in the prokaryotic cyanobacteria, but not in vertebrates. In some cases, green algae show higher or similar sensitivity compared to cyanobacteria (e.g. [78]). Thus, a wider array of different green algae and cyanobacteria should be assessed, as proposed in the draft guideline [14].

However, additional effort is necessary to adapt the ERA procedure to further protect microbial communities in the environment, which is not currently the protection goal for the ERA $[79,80]$, and potentially also incorporate the risk of antimicrobial resistance development [81]. Tell and colleagues have shown that the PNEC for antimicrobial resistance may be even lower than the PNEC for aquatic ecotoxicity in a large proportion of cases [82]. Focussing solely on ecotoxicological effects may not suffice to cover the risk of antimicrobial resistance development. Consequently, an adapted approach will be necessary.

For substances affecting the endocrine system, Fig. 2 shows that algae are never the most sensitive species. Thus, regulatory risk analyses should focus on fish, while the testing of algae does not seem necessary. Additionally, depending on the mechanism of action, testing aquatic invertebrate taxa might be appropriate due to the phylogenetic conservation of mechanistic target units in vertebrates and groups of invertebrates [83]. Steroid hormones and their receptors, as well as steroidogenic pathways, play major roles in the development of vertebrates, while not being functional in algae and often to a lesser degree in invertebrates [84, 85]. Again, this is in line with the pharmaceutical modes of action. Furthermore, the fact that the effect concentrations for this substance group were mainly derived from long-term fish sexual development or fish full life cycle studies, instead of fish early life stage tests, could also contribute to the observed highly sensitive reactions. From a scientific point of view, the application of these elaborate tests is reasonable, because hormone-active substances are likely to affect endpoints like reproduction and sexual development, which are not covered by short term or early life stage tests.
For other groups of substances, such strategies for "tailored risk assessment" are not supported by the current database. Either the tests showed comparable sensitivity of the taxa for a single substance, or different taxa were most susceptible to different APIs of the same groupindicating that the testing of all three taxa is necessary (see Fig. 2). Sometimes, there were only data on one or very few APIs of a group, which does not allow a sound conclusion on the group as a whole. It has to be kept in mind that these analyses are based on a rough grouping into twelve different categories. When these are divided into even smaller subgroups, this results in a vast array of groups, with only very few data points in each group and no conclusions possible. Approaches with grouping based on specific pharmacological modes of action [26, 86, 87] may help in this respect, but will also need more data to allow conclusions to be drawn. As more data will become available in the future, further tailored risk assessment strategies for other substance groups may be developed.

The current conclusions on sensitivity are only based on the three aquatic taxa used in environmental risk assessment of human pharmaceuticals-algae, daphnids and fish, and the respective established endpoints. However, other organism groups, like, e.g. molluscs or amphibians, may also be highly susceptible to certain substances [83, 88, 89]. Further scientific research in this area will help to decide on adding further organism groups and alternative endpoints to future risk assessment strategies.

\section{Persistence assessment}

The evaluation of persistence showed that just a few APIs were readily biodegradable. This means that the majority of the substances have no potential to ultimately degrade during sewage treatment [50], but are just transformed or persist in their original form in sewage water or sludge. This result is in line with studies about the elimination of pharmaceuticals during sewage treatment (e. g. [61, 90, 91] [92]). In these studies, transformation or persistence of the APIs was shown, but only in few cases was a complete elimination (mineralisation) observed. Substances which were not readily biodegradable were classified as potentially persistent.

The results of the water-sediment simulation tests showed that more than $50 \%$ of the tested substances are persistent; the majority of those are even very persistent. This is one explanation besides continuous emission by production and use for findings of APIs all over the world $[93,94]$. Mathematical simulations of the concentration of APIs in the Rhine River have shown that degradation depends highly on the physical conditions in the stream. Degradation was especially for larger streams no 
significant sink for APIs in the environment [95]. Measurements in the river Thames also showed increasing concentrations of pharmaceuticals downstream, with decreasing concentrations for samples in the estuary because of higher dilution [96].

It should be noted that the available database is only sufficient to make conclusions on persistence of the APIs themselves. Therefore, transformation products (TPs) were not included in this evaluation. Studies on the occurrence and fate of TPs show that, in addition to the API, many environmental organisms are exposed to TPs (e.g. [97-99]).

More than a half of the tested substances will be available in their pharmaceutically active form for four months and longer, which is considerably longer than the duration of the standard effect tests in Phase II. Additionally, for a relevant proportion of substances half-lives are extremely long ( $12 \%$ of APIs have a $\mathrm{DT}_{50}>1000 \mathrm{~d}$ ). It should be noted that the recommended test duration of OECD TG 308 studies is $100 \mathrm{~d}$. Consequently, all depicted half-lives above $100 \mathrm{~d}$ were based on extrapolations, with increasing uncertainty for higher values. Furthermore, limitations of the OECD 308 were discussed in recent literature $[55,100]$. This was addressed by using the total system half-lives as persistence indicator. Still, one must be careful when comparing specific results from different tests in detail. Different environmental conditions in each test system and variations in the technical guidance, e.g. different geometrical dimensions of test vessels, can influence the outcome.

In spite of the limitations, it is expected that the overall picture of the distribution of persistence gives valuable information on the environmental behaviour. It may be assumed for substances with such high degradation halflives that nearly no biotic or abiotic degradation will be observed in the environment. Thus, these APIs persist (and thus accumulate if constantly released to the environment). Consequently, with the constant exposure due to continuous emission from STP linked with high persistence, long-term effects for environmental organisms cannot be excluded. The comparison with the T-criteria showed that $30 \%$ of the persistent substances exert toxic effects to environmental organisms at low concentrations; the majority of these substances had half-lives longer than 6 months. In a risk assessment approach, it may not be possible to derive reliable PEC values as there is a continuous increase in environmental compartments over decades. Cousins et al. (2019) [101] discussed that high persistence alone should be established as sufficient basis for regulation, and named this the "P-sufficient approach". At the moment there is no scientifically sound solution how to treat such substances in risk assessments. Currently, only substances which are persistent, bioaccumulative and toxic (PBT), or very persistent and very bioaccumulative, are categorised to be $\mathrm{PBT}$ or $\mathrm{vPvB}$ in a hazard assessment.

\section{Terrestrial trigger evaluation and effect assessment}

For the soil compartment two questions should be answered. Is the current trigger value suitable for the soil risk assessment? If a $\mathrm{PEC}_{\text {soil }}$ trigger is more reliable, can the recent data base be used for the derivation of such a trigger value?

The results of the SimpleTreat 4.0 modelling and the literature screening show that risks for soils might be overlooked because some substances accumulate in relevant concentrations in sewage sludge, which may then be applied on land, but currently do not have to undergo a soil risk assessment. These findings are supported by a review from Verlicchi and Zambello about the occurrence of APIs in different forms of sewage sludge [6]. Many APIs were reported, which have not been subjected to terrestrial assessment due to the fact that their $K_{o c}$ was below the trigger value. They were found in sewage sludge in quantifiable concentrations-especially APIs with high dosage and high market penetration like ibuprofen and diclofenac $[6,63,64]$. Finally, terrestrial risks were calculated particularly for hormones and antibiotics [6]. However, the risk assessment differs much from that in the guideline as data from aquatic toxicity were extrapolated to terrestrial PNECs, so a comparison with the data in the present study is not scientifically sound.

In the new draft guideline [14], the trigger for soil assessment is expanded by a modified trigger value combining adsorption with the $\mathrm{PEC}_{\mathrm{sw}}$ from Phase I, which also considers possible refinements. Decisive input values for the calculation of $\mathrm{PEC}_{\text {soil }}$ are the fraction sorbed to sludge and the local emission to wastewater $\left(\mathrm{E}_{\text {local }}\right)$ which correlates with the $\mathrm{PEC}_{\mathrm{sw}}$. Both known parameters are used as simple stepwise trigger systems instead of directly calculating a $\mathrm{PEC}_{\text {soil }}$ in Phase II Tier A. However, the two parameters can be easily transformed into $\mathrm{PEC}_{\text {soil }}$ values. For trigger values proposed in the guideline, the resulting $\mathrm{PEC}_{\text {soil }}$ would range from 15 to $34 \mu \mathrm{g} / \mathrm{kg}$ (see Additional file 1: Table S5).

Knowledge on terrestrial effect data might be helpful to derive a trigger value for soil. However, due to the structure of the current guideline, ecotoxicity data for the terrestrial compartment were only available for substances with high $\mathrm{K}_{\mathrm{oc}}$ values $(>10,000 \mathrm{~L} / \mathrm{kg})$. This leads to a bias of the dataset. An estimate of the ecotoxicity of substances with lower $\mathrm{K}_{\mathrm{oc}}$, but still high potential concentrations in soil (e.g. through high overall consumption), is not possible. The ecotoxicity data are not fully suitable to derive a trigger value based on possible effects as provided for the aquatic risk assessment. Maynard et al. [102] derived 
a PEC-soil trigger for human pharmaceuticals based on terrestrial effect data for 40 APIs, available from EPARs and internal company databases. In total, $92.5 \%$ of lowest PNECs (36 of 39 APIs, excluding data on soil microorganisms) were higher than $100 \mu \mathrm{g} / \mathrm{kg}$. This is a similar finding to the 43 of $47 \mathrm{APIs}$ with $\mathrm{NOEC} / \mathrm{EC}_{10}$ higher than $1 \mathrm{mg} / \mathrm{kg}$ in the present publication, given that an assessment factor of 10 was used to calculate PNECs from NOECs. This finding is not surprising, considering that there is most likely a large overlap in the databases used for both analyses. However, this also means that both analyses also suffer from the same bias of only including data on highly adsorbing APIs. Maynard et al. [102], proposed a PEC action limit of $100 \mu \mathrm{g} / \mathrm{kg}$ for terrestrial ERA as an alternative to the approach proposed in the draft guideline $[14,102]$ as the majority of investigated PNECs for human APIs are larger than this trigger and would be in line with the approach for veterinary medicinal products [103]. However, it has to be considered that for approx. $7.5 \%$ of APIs the PNEC is below this proposed action limit. Hence, the question arises if this proposed action limit achieves the desired protection level, especially considering the aforementioned restrictions of the database. Furthermore, previous evaluations of regulatory data available to the UBA have shown that more than $20 \%$ of veterinary APIs have PNECs below $100 \mu \mathrm{g} /$ $\mathrm{kg}$ [104]. Hence, it may not be appropriate to align a new PEC action limit for human APIs to an outdated action limit for veterinary APIs, which is likely not protective enough. However, it must be kept in mind that veterinary APIs mainly belong to the pharmaceutical groups of antibiotics and antiparasitics. This complicates a comparison between the entirety of veterinary APIs and human APIs, which consist of a more diverse array of pharmaceutical groups.

Generally, a $\mathrm{PEC}_{\text {soil }}$ trigger considers the amount of a substance in sewage sludge in a scientifically sound way. Two APIs showed PNECs below $100 \mu \mathrm{g} / \mathrm{kg}$, but none was lower than $34 \mu \mathrm{g} / \mathrm{kg}$, which is the maximum $\mathrm{PEC}_{\text {soil }}$ corresponding to the terrestrial trigger in the draft guideline. The trigger approach proposed in the draft guideline [14] offers a higher level of protection. Terrestrial effect data on further APIs, obtained in compliance to the data requirements of the new guideline, will possibly allow a refinement of the trigger value at a later time stage. In addition, it should be checked in the future if the residues of APIs in soils are influenced by wastewater reuse for irrigation, which is practised in several EU-member states and considered for expansion by the EU [105].

One conclusion that can be drawn is that the test on earthworm acute toxicity does not yield relevant results for the assessment of human pharmaceuticals. In none of the cases were effects observed at the highest tested concentration, which was usually much higher than predicted environmental concentrations. From this perspective, it seems appropriate that the new draft guideline [14] proposes to replace the test on earthworm acute toxicity [20], with a test on earthworm reproduction [21]. Additionally, long-term testing in soil treated with APIs better fits the exposure scenario, where the active substances enter soil via sewage sludge application and are available in the soil over a long duration. Most human APIs have shown $\mathrm{DT}_{50}$ values longer than $14 \mathrm{~d}$ (test duration of the acute earthworm test). Replacing acute with long-term testing will help to base the evaluation of terrestrial risk on more relevant effect testing. For the same scientific reasons long-term data are also used in the assessment of veterinary medicinal products [106].

\section{Conclusions}

The environmental risk assessment during the regulatory marketing authorisation process for human medicinal products, which started in 2006, has generated a considerable data base. Although there was a data gap for several substance classes, the used data base still allowed a sound scientific evaluation. The results of our analyses strengthen some approaches in the current guideline [10], while others are in need for revision. These are the lessons we have learnt:

\section{Aquatic effect studies: action limit}

$10 \mathrm{ng} / \mathrm{L}$ are appropriate as PEC action limit.

As stated in the current guideline for environmental risk assessment, the present action limit for a more detailed Phase II assessment-10 ng/L_- "may be revised in future versions of the guideline when a sufficient amount of chronic data is available" [10]. The data on long-term aquatic toxicity evaluated in our publication show that the current PEC action limit of $10 \mathrm{ng} / \mathrm{L}$ is in a relevant range. Therefore, the established action limit should not be changed. The new draft guideline [14] proposes to use the same action limit.

\section{Aquatic effect studies: comparison of sensitivity}

Tailored risk assessment for antibiotics and endocrineactive substances possible.

For most APIs the environmental risks should be assessed based on a wide ecological range of test organisms and trophic levels, e.g. algae, invertebrates and fish for the aquatic compartment. However, the effect data evaluated in our study also show that a more specific tailored risk assessment should be performed for antibiotics and endocrine-active substances. The proposal in the 
new draft guideline considers a tailored assessment for these two substance groups.

\section{Persistence assessment}

APIs show high persistence in the environment.

Data for ready biodegradability show that the majority of APIs or their transformation products reach the surface water after sewage treatment as mineralisation is low. The data from water sediment simulation tests demonstrate that around half of the APIs are persistent or very persistent and a significant part is highly persistent. The combination of very high persistence and continuous emission may lead to accumulation in environmental media, particularly sediments and soils. These substances will remain in the environment. In the draft guideline, such substances cannot be identified anymore, because the water-sediment simulation test is no longer part of the base dataset. A scientifically sound solution how to identify and treat highly persistent APIs in risk assessments is needed.

\section{Terrestrial fate and effects assessment}

Terrestrial assessment strategy needs to be improved.

The current trigger value for terrestrial ERA may overlook relevant substances in sewage sludge, and the required ecotoxicity tests are not fully adequate. An adjusted strategy should include a trigger value that not only considers physico-chemical properties of the API, but also the amount of usage. Furthermore, effects assessment should be based on long-term toxicity instead of acute toxicity. The proposed approach of the new draft guideline [14] could help generate more relevant data in the future, to identify risks of APIs that were formerly overlooked.

\section{Outlook}

Most of these points are, to a certain extent, addressed in the proposed draft guideline [14]. The proposed approaches for the risk assessment are supported by our evaluated data. Therefore, these changes will hopefully also find their way into the upcoming final guideline.

\footnotetext{
Abbreviations

API: Active pharmaceutical ingredient; ATC: Anatomical therapeutic chemical classification; BCF: Bioconcentration factor; $\mathrm{DT}_{50}$ : Time taken for $50 \%$ of the substance to disappear from the total system due to degradation and forming of non-extractable residues; EAS: Endocrine-active substance; ECHA: European Chemical Agency; $\mathrm{EC}_{10}: 10 \%$ Effect concentration; $\mathrm{E}_{\text {local }}$ : Local emission from sewage treatment plant; EMA: European Medicines Agency; EPAR: European Public Assessment Report; ERA: Environmental risk assessment; EU: European Union; $F_{\text {stp: }}$ : Fraction of substance partitioning to sewage sludge; $\mathrm{K}_{\mathrm{d}}$ : Distribution coefficient; $\mathrm{K}_{\mathrm{oc}}$ : Organic carbon normalised adsorption coefficient; $\mathrm{LC}_{50}$ : $50 \%$ Lethal concentration; $\log D_{\text {ow: }}$ : Logarithm of ion corrected octanol/water partitioning coefficient; $\log \mathrm{K}_{\text {ow: }}$ : Logarithm of octanol/water partitioning
}

coefficient; NOEC: No observed effect concentration; NER: Non-extractable residues; OECD: Organisation for Economic Co-operation and Development; PAR: Public assessment report; PBT: Persistent, bioaccumulative and toxic; PEC, $\mathrm{PEC}_{\text {sw' }}, \mathrm{PEC}_{\text {soil }}$ : Predicted environmental concentration (in surface water, in soil); PNEC: Predicted no effect concentration; RQ: Risk quotient; SSD: Species sensitivity distribution; STP: Sewage treatment plant; UBA: German Environment Agency (Umweltbundesamt); vPvB: Very persistent and very bioaccumulative.

\section{Supplementary Information}

The online version contains supplementary material available at https://doi. org/10.1186/s12302-021-00503-0.

Additional file 1: Figure S1. Correlation of lipophilicity (highest $\log \mathrm{D}_{\text {ow }}$ in environmentally relevant $\mathrm{pH}$-range) and toxicity (lowest NOEC or $\mathrm{EC}_{10}$ ) in human APIs $(n=172)$. Substances with high $\log \mathrm{D}_{\text {ow }}$ tend to have lower effect concentrations. However, there are still several APIs with $\log \mathrm{D}_{\text {ow }}<$ 3 and NOEC $<1 \mu \mathrm{g} / \mathrm{L}$. Figure S2. Depiction of the lowest available NOEC or $\mathrm{EC}_{10}$ available per $\mathrm{API}$, arranged in ascending order. The plot is based on the full dataset (309 APIs). APIs with logD ow larger than 3 are coloured orange, $A P I s$ with $\log D_{\text {ow }}$ lower than 3 are coloured black. If no reliable data on the $\log \mathrm{D}_{\text {ow }}$ is available, the API is coloured grey. Two theoretical distributions are fit (normal distribution based on either log10 or on Box-Cox-transformed dataset). The fitted distribution and calculated $5 \%$ and $1 \%$ NOECs are marked in blue $(\log 10)$ and red (Box-Cox). The $95 \%$ confidence interval (Cl) for the "Box-Cox" model is shown as dashed black line. The $1 \%, 5 \%$ and $50 \%$ level are depicted as dashed grey lines. Figure S3. Information on the fitted distribution and goodness-of-fit, based on the Box-Cox-transformed $(\lambda=0.0202$ ) adjusted dataset (excluding endocrine-active substances and antiparasitics). Figure S4. Information on the fitted distribution and goodness-of-fit, based on the log10-transformed adjusted dataset (excluding endocrine-active substances and antiparasitics). Figure S5. Information on the fitted distribution and goodness-of-fit, based on the Box-Cox-transformed $(\lambda=0.0606)$ full dataset (including all API groups). Figure S6. Information on the fitted distribution and goodness-of-fit, based on the log10-transformed full dataset (including all API groups). Figure S7. Overview of the lowest NOECs/EC 10 , sorted by pharmaceutical group. Bold lines depict the median, boxes the $25 \%$ and $75 \%$ percentiles, whiskers the 1.5 interquantile ranges. Each black dot represents a single API. A detailed description of the pharmaceutical groups is given in Table S1. Figure S8. Overview of the sensitivity difference between most and least sensitive taxon for 182 APIs, displayed as the quotient of the highest NOEC divided by the lowest NOEC per API. Bold lines depict the median, boxes the $25 \%$ and $75 \%$ percentiles, whiskers the 1.5 interquantile ranges. Each black dot represents a single API. A detailed description of the pharmaceutical groups is given in Table S1. Contrast agents and antiparasitics are excluded because there was data on no, or only one API per group, respectively. Figure S9. Overview of terrestrial effect concentrations, sorted by pharmaceutical group. Bold lines depict the median of the lowest overall effect concentrations, boxes the $25 \%$ and $75 \%$ percentiles, whiskers the 1.5 interquantile ranges. Endpoints for each organism group are illustrated by coloured dots (uncensored values) or crosses (censored values). Green represents plant NOECs/EC 10 s, orange collembolan NOECs/EC 10 s and blue annelid $L_{50}$ s. A detailed description of the pharmaceutical groups is given in Table S1. Figure S10. Depiction of the lowest available NOEC or $\mathrm{EC}_{10}$ available per API, arranged in ascending order. The plot is based on an adjusted dataset only including API with data on all three aquatic taxa; excluding antibiotics, antivirals, antimycotics, antiparasitics and endocrine-active substances (147 APIs). APIs with $\log D_{\text {ow }}$ larger than 3 are coloured orange, $A P I s$ with $\log D_{\text {ow }}$ lower than 3 are coloured black. If no reliable data on the $\log D_{\text {ow }}$ is available, the API is coloured light grey. Two theoretical distributions are fit (normal distribution based on either log 10 or on Box-Cox-transformed dataset). The fitted distribution and calculated $5 \%$ and $1 \%$ NOECs are marked in blue (log10) and red (Box-Cox). The $95 \%$ confidence interval $(\mathrm{Cl})$ for the "Box-Cox" model is shown as dashed black line. The $1 \%$ and $5 \%$ level are depicted as dashed grey lines. Figure S11. Overview on the total system $\mathrm{DT}_{50}\left(12^{\circ} \mathrm{C}\right)$ of $196 \mathrm{APIs}$, sorted by pharmaceutical group. Bold lines depict the median, boxes the $25 \%$ and $75 \%$ percentiles, whiskers the 1.5 
interquantile ranges. Each black dot represents a single API. The criteria for classification as "persistent" ( $\left(\mathrm{DT}_{50} \geq 120 \mathrm{~d}\right.$ ) and "very persistent" $\left(\mathrm{DT}_{50} \geq\right.$ $180 \mathrm{~d}$ ) are illustrated in blue and red, respectively. A detailed description of the pharmaceutical groups is given in Table S1. Table S1. Description of the pharmaceutical groups and the respective substances, which are categorised in these groups. Table S2. Metrics and results of fitted theoretical distributions for API effect concentrations (NOEC/EC 10 ). Two different datasets were explored: the full dataset and an adjusted dataset excluding endocrine-active substances and antiparasitics. Two different models were chosen: a normal distribution fitted to the Box-Cox-transformed dataset, and a normal distribution fitted to a log 10-transformed dataset. The depicted model metrics are based on the transformed data, $5 \%$ and $1 \% \mathrm{NOECs} /$ percentiles and confidence intervals are backtransformed. AICs are not directly comparable between models, because both are based on differently transformed datasets. Table S3. Percentiles of total system DT $T_{50}\left(12^{\circ} \mathrm{C}\right)$ of $196 \mathrm{APIs}$ displayed in Figure 3. Data originated from

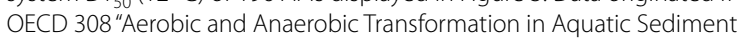
Systems" studies. DT 50 values higher than $100 \mathrm{~d}$ are extrapolated. Table S4. Maximum concentrations of APIs in sewage sludge, reported in publicly available literature. Table $\mathbf{S 5}$. Combined trigger values $\mathrm{K}_{\mathrm{oc}}$ and $\mathrm{PEC} \mathrm{C}_{\mathrm{sw}}$ for substances entering a risk assessment for soil organisms and their corresponding values as $\mathrm{F}_{\text {stp }}{ }^{*}{ }^{-}$sludge, $\mathrm{DOSE}_{\mathrm{As}}, \mathrm{E}_{\mathrm{local}}$ and $\mathrm{PEC}_{\text {soil. }}$. Table $\mathbf{S 6}$. List of substances with at least one valid aquatic NOEC/EC 10 available. The respective pharmaceutical group (explained in Table $\mathrm{S} 1$ ) is indicated for each substance. The column "effect data" describes whether aquatic (A) and/or terrestrial $(T)$ effect data were available. When data were available for all three organism groups, this is indicated by (3). The columns "Watersediment simulation data" and " $\mathrm{K}_{\mathrm{oc}}$ data" indicate whether reliable half-lives from OECD308, and reliable adsorption coefficient data were available. All substances with aquatic effect data were included in the "full dataset", endocrine-active substances and antiparasitics were excluded from the "adjusted dataset", which was used for the derivation of an aquatic PEC action limit. The last column indicates whether the API was also evaluated in the publication of Gunnarsson et al. (2019) and if the same lowest aquatic NOEC was used $(=)$ or not $(\neq)$. (PDF 1378 KB)

\section{Acknowledgements}

We thank Ute Brandt, Sieglinde Zahorszki, Susanne Schmitz and Jasmin Brückner for their help with the data collection, and Thomas Gräff for his help with the statistical analyses. Furthermore, we thank Ina Ebert, Silke Hickmann, Caroline Moermond, Ines Rönnefahrt, Laila Sortvik Nilssen and Rhys Whomsley for their helpful discussions on the manuscript draft, and five anonymous reviewers for their constructive feedback.

\section{Authors' contributions}

SS and JB compiled and evaluated the data on aquatic and terrestrial effect studies. DG, PS and AH complied and evaluated the data on environmental fate and persistence. PS conducted the literature search on APIs in sewage sludge. SS performed the statistical analyses and created the graphs. SS, DG, $\mathrm{AH}$ and JB wrote and finalised the manuscript. All authors read and approved the final manuscript.

\section{Funding}

Open Access funding enabled and organized by Projekt DEAL. This publication was created as part of the authors ' work at the UBA. There was no additional funding.

\section{Availability of data and materials}

Due to the confidentiality of data submitted during authorisation processes, the database cannot be made publicly available. The supplementary information contains a list of all substances included in the analyses, without the respective endpoints.

\section{Declarations}

Ethics approval and consent to participate Not applicable.

\section{Consent for publication}

Not applicable.

\section{Competing interests}

The authors declare that they have no competing interests.

Received: 22 February 2021 Accepted: 8 May 2021

Published online: 02 June 2021

\section{References}

1. Ebele AJ, Abou-Elwafa Abdallah M, Harrad S (2017) Pharmaceuticals and personal care products (PPCPS) in the freshwater aquatic environment. Emerg Contam 3(1):1-16. https://doi.org/10.1016/j.emcon.2016. 12.004

2. Daughton CG, Ternes TA (1999) Pharmaceuticals and personal care products in the environment: agents of subtle change? Environ Health Perspect 107(SUPPL. 6):907-938. https://doi.org/10.1289/ehp.99107 s6907

3. Halling-Sørensen B, Nors Nielsen S, Lanzky PF, Ingerslev F, Holten Lützhøft HC, Jørgensen SE (1998) Occurrence, fate and effects of pharmaceutical substances in the environment-a review. Chemosphere 36(2):357-393. https://doi.org/10.1016/S0045-6535(97)00354-8

4. Aus Der BeekT, Weber FA, Bergmann A, Hickmann S, Ebert I, Hein A, Küster A (2016) Pharmaceuticals in the environment-Global occurrences and perspectives. Environ Toxicol Chem 35(4):823-835. https:// doi.org/10.1002/etc.3339

5. Yang Y, Ok YS, Kim KH, Kwon EE, Tsang YF (2017) Occurrences and removal of pharmaceuticals and personal care products (PPCPS) in drinking water and water/sewage treatment plants: a review. Sci Total Environ 596-597:303-320. https://doi.org/10.1016/j.scitotenv.2017.04. 102

6. Verlicchi P, Zambello E (2015) Pharmaceuticals and personal care products in untreated and treated sewage sludge: occurrence and environmental risk in the case of application on soil-a critical review. Sci Total Environ 538:750-767. https://doi.org/10.1016/j.scitotenv.2015. 08.108

7. Oaks JL, Gilbert M, Virani MZ, Watson RT, Meteyer CU, Rideout BA, Shivaprasad HL, Ahmed S, Chaudhry MJl, Arshad M, Mahmood S, Ali A, Khan AA (2004) Diclofenac residues as the cause of vulture population decline in Pakistan. Nature 427(6975):630-633. https://doi.org/10.1038/ nature02317

8. Kidd KA, Blanchfield PJ, Mills KH, Palace VP, Evans RE, Lazorchak JM, Flick RW (2007) Collapse of a fish population after exposure to a synthetic estrogen. Proc Natl Acad Sci 104(21):8897-8901. https://doi.org/10. 1073/pnas.0609568104

9. EU (2001) Directive 2001/83/EC of the European Parliament and of the Council of 6 November 2001 on the Community code relating to medicinal products for human use, vol L311, pp 67-128. Official Journal of the European Union

10. EMA (2006) EMEA/CHMP/SWP/4447/00 corr 2-guideline on the environmental risk assessment of medicinal products for human use. In: Agency, EM ed.. London., https://www.ema.europa.eu/documents/ scientific-guideline/guideline-environmental-risk-assessment-medic inal-products-human-use-first-version_en.pdf

11. EMA (2016) EMA/CHMP/SWP/44609/2010 Rev. 1-Questions and answers on 'Guideline on the environmental risk assessment of medicinal products for human use'. In: Agency EM ed. London. https://www. ema.europa.eu/en/questions-answers-guideline-environmental-riskassessment-medicinal-products-human-use

12. EU (2019) European Union Strategic Approach to Pharmaceuticals in the Environment. In: communication from the commission to the European parliament, the council and the European Economic and Social Committee. European Commission, Brussels

13. Whomsley R, Brendler-Schwaab S, Griffin E, Jensen J, Moermond C, Scholz B, Nilssen LS, Stemplewski H, Roennefahrt I (2019) Commentary on the draft revised guideline on the environmental risk assessment of 
medicinal products for human use. Environ Sci Eur 31 (1):17. https://doi. org/10.1186/s12302-019-0198-9

14. EMA (2018) EMEA/CHMP/SWP/4447/00 Rev. 1 - Guideline on the environmental risk assessment of medicinal products for human use - Draft. In. European Medicines Agency_Committee for Medicinal Products for Human Use (CHMP), London. https://www.ema.europa.eu/docum ents/scientific-guideline/draft-guideline-environmental-risk-asses sment-medicinal-products-human-use-revision-1_en.pdf

15. OECD (2002) Test No. 308: aerobic and anaerobic transformation in aquatic sediment systems. Doi: https://doi.org/10.1787/9789264070 523-en

16. OECD (2004) Test No. 218: sediment-water chironomid toxicity using spiked sediment. Doi: https://doi.org/10.1787/9789264070264-en

17. OECD (2004) Test No. 219: sediment-water chironomid toxicity using spiked water. Doi: https://doi.org/10.1787/9789264070288-en

18. OECD (2004) Test No. 225: sediment-water lumbriculus toxicity test using spiked sediment. Doi: https://doi.org/10.1787/9789264067356-en

19. OECD (2010) Test No. 233: sediment-water chironomid life-cycle toxicity test using spiked water or spiked sediment. Doi: https://doi.org/10. 1787/9789264090910-en

20. OECD (1984) Test No. 207: earthworm, acute toxicity tests. Doi: https:// doi.org/10.1787/9789264070042-en

21. OECD (2016) Test No. 222: earthworm reproduction test (Eisenia fetida/Eisenia andrei). Doi: https://doi.org/10.1787/9789264264496-en

22. EMA (2021) National authorisation procedures. https://www.ema. europa.eu/en/about-us/what-we-do/authorisation-medicines. Accessed 30 Apr 2021

23. Cunha DL, Mendes MP, Marques M (2019) Environmental risk assessment of psychoactive drugs in the aquatic environment. Environ Sci Pollut Res 26(1):78-90. https://doi.org/10.1007/s11356-018-3556-z

24. Desbiolles F, Malleret L, Tiliacos C, Wong-Wah-Chung P, Laffont-Schwob I (2018) Occurrence and ecotoxicological assessment of pharmaceuticals: Is there a risk for the Mediterranean aquatic environment? Sci Total Environ 639:1334-1348. https://doi.org/10.1016/j.scitotenv.2018.04.351

25. Godoy AA, Kummrow F, Pamplin PAZ (2015) Occurrence, ecotoxicological effects and risk assessment of antihypertensive pharmaceutical residues in the aquatic environment-a review. Chemosphere 138:281-291. https://doi.org/10.1016/..chemosphere.2015.06.024

26. Gunnarsson L, Snape JR, Verbruggen B, Owen SF, Kristiansson E, Margiotta-Casaluci L, Österlund T, Hutchinson K, Leverett D, Marks B, Tyler CR (2019) Pharmacology beyond the patient—-the environmental risks of human drugs. Environ Int 129:320-332. https://doi.org/10.1016/j.envint. 2019.04.075

27. Küster A, Bachmann J, Brandt U, Ebert I, Hickmann S, Klein-Goedicke J, Maack G, Schmitz S, Thumm E, Rechenberg B (2009) Regulatory demands on data quality for the environmental risk assessment of pharmaceuticals. Regul Toxicol Pharmacol RTP 55(3):276-280. https:// doi.org/10.1016/j.yrtph.2009.07.005

28. Moermond C, Beasley A, Breton R, Junghans M, Laskowski R, Solomon K, Zahner H (2017) Assessing the reliability of ecotoxicological studies: an overview of current needs and approaches. Integr Environ Assess Manag 13(4):640-651. https://doi.org/10.1002/ieam.1870

29. EMA (2021) European public assessment reports: background and context https://www.ema.europa.eu/en/medicines/what-we-publi sh-when/european-public-assessment-reports-background-context. Accessed 30 Apr 2021

30. Agency HOM (2021) MRI product index. https://mri.cts-mrp.eu/Human/ about. Accessed 30 Apr 2021

31. OECD (2011) Test No. 201: freshwater alga and cyanobacteria, growth inhibition test. Doi: https://doi.org/10.1787/9789264069923-en

32. OECD (2012) Test No. 211: Daphnia magna reproduction test. Doi: https://doi.org/10.1787/9789264185203-en

33. OECD (2013) Test No. 210: fish, early-life stage toxicity test. Doi: https:// doi.org/10.1787/9789264203785-en

34. OECD (2008) Detailed review paper on fish life-cycle tests, vol. Series on testing and assessment no. 95. organisation for economic cooperation and development, Paris

35. OECD (2011) Test No. 234: fish sexual development test. Doi: https://doi. org/10.1787/9789264122369-en

36. Belanger S, Barron M, Craig P, Dyer S, Galay-Burgos M, Hamer M, Marshall S, Posthuma L, Raimondo S, Whitehouse P (2017) Future needs and recommendations in the development of species sensitivity distributions: Estimating toxicity thresholds for aquatic ecological communities and assessing impacts of chemical exposures. Integr Environ Assess Manag 13(4):664-674. https://doi.org/10.1002/ieam.1841

37. Kon Kam King G, Veber P, Charles S, Delignette-Muller ML (2014) MOSAIC_SSD: a new web tool for species sensitivity distribution to include censored data by maximum likelihood. Environ Toxicol Chem 33(9):2133-2139. https://doi.org/10.1002/etc.2644

38. Box GEP, Cox DR (1964) An analysis of transformations. J Roy Stat Soc: Ser B (Methodol) 26(2):211-243. https://doi.org/10.1111/j.2517-6161. 1964.tb00553.x

39. R Core Team (2018) R: A language and environment for statistical computing. R Foundation for Statistical Computing, Vienna, Austria

40. RStudio Team (2016) RStudio: integrated development for R. RStudio Inc, Boston, MA

41. Venables WN, Ripley BD (2002) Modern applied statistics with S, 4th edn. Springer, New York

42. Lemon J (2006) Plotrix: a package in the red light district of R. R-News 6(4):8-12

43. Delignette-Muller ML, Dutang C (2015) fitdistrplus: an R package for fitting distributions. J Stat Softw 64(4):1-34. https://doi.org/10.18637/ jss.v064.i04

44. Fox J (2019) Weisberg S (2019) An R companion to applied regression, 3rd edn. Sage, Thousand Oaks, CA

45. Dutang C, Goulet V, Pigeon M (2008) Actuar: An R package for Actuarial Science. J Stat Softw 25(7):1-37

46. OECD (1995) Test No. 107: partition coefficient (n-octanol/water): Shake Flask Method. Doi: https://doi.org/10.1787/9789264069626-en

47. OECD (2006) Test No. 123: partition coefficient (1-Octanol/Water): SlowStirring Method. Doi: https://doi.org/10.1787/9789264015845-en

48. OECD (1992) Test No. 301: ready biodegradability. Doi: https://doi.org/ $10.1787 / 9789264070349$-en

49. OECD (2014) Test No. 310: ready biodegradability —CO2 in sealed vessels (Headspace Test). Doi: https://doi.org/10.1787/9789264224506-en

50. Guhl W, Steber J (2006) The value of biodegradation screening test results for predicting the elimination of chemicals' organic carbon in waste water treatment plants. Chemosphere 63(1):9-16. https://doi. org/10.1016/j.chemosphere.2005.07.082

51. ECHA (2017) Guidance on information requirements and chemical safety assessment Chapter R.11: PBT/VPvB assessment. In: ECHA ed. https://echa.europa.eu/documents/10162/13632/information_requi rements_r11_en.pdf

52. FOCUS (2006) Guidance document on estimating persistence and degradation kinetics from environmental fate studies on pesticides in EU registration. Report of the FOCUS Work Group on Degradation Kinetics. In: EC ed. Sanco/10058/2005 version 2.0, 434 pp

53. Loeffler D, Hatz A, Albrecht D, Fligg M, Hogeback J, Ternes TA (2020) Determination of non-extractable residues in soils: towards a standardised approach. Environ Pollut 259:1 13826. https://doi.org/10.1016/j. envpol.2019.113826

54. Schäffer A, Kästner M, Trapp S (2018) A unified approach for including non-extractable residues (NER) of chemicals and pesticides in the assessment of persistence. Environ Sci Eur. https://doi.org/10.1186/ s12302-018-0181-X

55. Honti M, Fenner K (2015) Deriving persistence indicators from regulatory water-sediment studies - opportunities and limitations in OECD 308 data. Environ Sci Technol 49(10):5879-5886. https://doi.org/10. 1021 /acs.est.5b00788

56. OECD (2000) Test no. 106: adsorption—desorption using a batch equilibrium method. Doi: https://doi.org/10.1787/9789264069602-en

57. EPA U (1998) EPA: 712-C-98-298. Environmental Protection Agency; prevention, pesticides and toxic substances 7101

58. EMA (2016) Questions and answers on 'Guideline on the environmental risk assessment of medicinal products for human use'. In: EMA/CHMP/ SWP/44609/2010 Rev. 1. Committee for Medicinal Products for Human Use (CHMP)

59. Struijs, J (2014) SimpleTreat 4.0: a model to predict fate and emission of chemicals in wastewater treatment plants: Background report describing the equations. . In, vol. 601353005. RIVM, Bilthoven, The Netherlands

60. Google (2021) Google Scholar Search Engine. http://scholar.google. com 
61. Bisognin RP, Wolff DB, Carissimi E, Prestes OD, Zanella R (2019) Occurrence and fate of pharmaceuticals in effluent and sludge from a wastewater treatment plant in Brazil. Environ Technol (United Kingdom). https://doi.org/10.1080/09593330.2019.1701561

62. Ekpeghere KI, Lee JW, Kim HY, Shin SK, Oh JE (2017) Determination and characterization of pharmaceuticals in sludge from municipal and livestock wastewater treatment plants. Chemosphere 168:1211-1221. https://doi.org/10.1016/j.chemosphere.2016.10.077

63. Huber S, Remberger M, Kaj L, Schlabach M, Jörundsdóttir HT, Vester J, Arnórsson M, Mortensen I, Schwartson R, Dam M (2016) A first screening and risk assessment of pharmaceuticals and additives in personal care products in waste water, sludge, recipient water and sediment from Faroe Islands, Iceland and Greenland. Sci Total Environ 562:13-25. https://doi.org/10.1016/j.scitotenv.2016.03.063

64. Ivanová L, Mackulak T, Grabic R, Golovko O, Koba O, Staňová AV, Szabová P, Grenčíková A, Bodík I (2018) Pharmaceuticals and illicit drugs - a new threat to the application of sewage sludge in agriculture. Sci Total Environ 634:606-615. https://doi.org/10.1016/j.scitotenv.2018. 04.001

65. Lajeunesse A, Smyth SA, Barclay K, Sauvé S, Gagnon C (2012) Distribution of antidepressant residues in wastewater and biosolids following different treatment processes by municipal wastewater treatment plants in Canada. Water Res 46(17):5600-5612. https://doi.org/10. 1016/j.watres.2012.07.042

66. Peysson W, Vulliet E (2013) Determination of 136 pharmaceuticals and hormones in sewage sludge using quick, easy, cheap, effective, rugged and safe extraction followed by analysis with liquid chromatographytime-of-flight-mass spectrometry. J Chromatogr A 1290:46-61. https:// doi.org/10.1016/j.chroma.2013.03.057

67. Subedi B, Kannan K (2015) Occurrence and fate of select psychoactive pharmaceuticals and antihypertensives in two wastewater treatment plants in New York State, USA. Sci Total Environ 514:273-280. https:// doi.org/10.1016/j.scitotenv.2015.01.098

68. Subedi B, Lee S, Moon HB, Kannan K (2013) Psychoactive pharmaceuticals in sludge and their emission from wastewater treatment facilities in Korea. Environ Sci Technol 47(23):13321-13329. https://doi.org/10. 1021/es404129r

69. OECD (2006) Test no. 208: terrestrial plant test: seedling emergence and seedling growth test. Doi: https://doi.org/10.1787/9789264070066-en

70. OECD (2016) Test no. 232: collembolan reproduction test in soil. Doi: 9789264264601-en

71. Oelkers K, Floeter C (2019) The accessibility of data on environmental risk assessment of pharmaceuticals: Is the marketing authorisation procedure in conflict with the international right of access to environmental information? Environ Sci Eur. https://doi.org/10.1186/ s12302-019-0256-3

72. Lumaret JP, Errouissi F, Floate K, Römbke J, Wardhaugh K (2012) A review on the toxicity and non-target effects of macrocyclic lactones in terrestrial and aquatic environments. Curr Pharm Biotechnol 13(6):1004-1060

73. ECETOC (2014) Estimating toxicity thresholds for aquatic ecological communities from sensitivity distributions In: Workshop report, vol. No. 28. Brussels

74. Vestel J, Caldwell DJ, Constantine L, D'Aco VJ, Davidson T, Dolan DG, Millard SP, Murray-Smith R, Parke NJ, Ryan JJ, Straub JO, Wilson P (2016) Use of acute and chronic ecotoxicity data in environmental risk assessment of pharmaceuticals. Environ Toxicol Chem 35(5):1201-1212. https://doi. org/10.1002/etc.3260

75. Bittermann K, Spycher S, Goss KU (2016) Comparison of different models predicting the phospholipid-membrane water partition coefficients of charged compounds. Chemosphere 144:382-391. https://doi.org/10. 1016/j.chemosphere.2015.08.065

76. EU (2010) DIRECTIVE 2010/63/EU OF THE EUROPEAN PARLIAMENT AND OF THE COUNCIL of 22 September 2010 on the protection of animals used for scientific purposes. In, vol. L 276/33

77. Le Page G, Gunnarsson L, Snape J, Tyler CR (2017) Integrating human and environmental health in antibiotic risk assessment: a critical analysis of protection goals, species sensitivity and antimicrobial resistance. Environ Int. https://doi.org/10.1016/j.envint.2017.09.013

78. Kolar B, Arnuš L, Jeretin B, Gutmaher A, Drobne D, Durjava MK (2014) The toxic effect of oxytetracycline and trimethoprim in the aquatic environment. Chemosphere 115(1):75-80. https://doi.org/10.1016/j. chemosphere.2014.02.049

79. Le Page G, Gunnarsson L, Trznadel M, Wedgwood KCA, Baudrot V Snape J, Tyler CR (2019) Variability in cyanobacteria sensitivity to antibiotics and implications for environmental risk assessment. Sci Total Environ 695:133804. https://doi.org/10.1016/j.scitotenv.2019.133804

80. Brandt KK, Amézquita A, Backhaus T, Boxall A, Coors A, Heberer T, Lawrence JR, Lazorchak J, Schönfeld J, Snape JR, Zhu YG, Topp E (2015) Ecotoxicological assessment of antibiotics: a call for improved consideration of microorganisms. Environ Int 85:189-205. https://doi.org/10. 1016/j.envint.2015.09.013

81. Bengtsson-Palme J, Larsson DGJ (2016) Concentrations of antibiotics predicted to select for resistant bacteria: proposed limits for environmental regulation. Environ Int 86:140-149. https://doi.org/10.1016/j. envint.2015.10.015

82. Tell J, Caldwell DJ, Häner A, Hellstern J, Hoeger B, Journel R, Mastrocco F, Ryan JJ, Snape J, Straub JO, Vestel J (2019) Science-based targets for antibiotics in receiving waters from pharmaceutical manufacturing operations. Integr Environ Assess Manag 15(3):312-319. https://doi.org/ 10.1002/ieam.4141

83. Matthiessen P (2008) An assessment of endocrine disruption in Mollusks and the potential for developing internationally standardized mollusk life cycle test guidelines. Integr Environ Assess Manag 4(3):274-284 https://doi.org/10.1897/IEAM_2008-003.1

84. Ankley GT, LaLone CA, Gray LE, Villeneuve DL, Hornung MW (2016) Evaluation of the scientific underpinnings for identifying estrogenic chemicals in nonmammalian taxa using mammalian test systems. Environ Toxicol Chem 35(11):2806-2816. https://doi.org/10.1002/etc.3456

85. Coady KK, Biever RC, Denslow ND, Gross M, Guiney PD, Holbech H, Karouna-Renier NK, Katsiadaki I, Krueger H, Levine SL, Maack G, Williams M, Wolf JC, Ankley GT (2017) Current limitations and recommendations to improve testing for the environmental assessment of endocrine active substances. Integr Environ Assess Manag 13(2):302-316. https:// doi.org/10.1002/ieam.1862

86. Santos R, Ursu O, Gaulton A, Bento AP, Donadi RS, Bologa CG, Karlsson A, Al-Lazikani B, Hersey A, Oprea TI, Overington JP (2016) A comprehensive map of molecular drug targets. Nat Rev Drug Discov 16(1):19-34. https://doi.org/10.1038/nrd.2016.230

87. Verbruggen B, Gunnarsson L, Kristiansson E, Österlund T, Owen SF, Snape JR, Tyler CR (2018) ECOdrug: a database connecting drugs and conservation of their targets across species. Nucleic Acids Res 46(D1):D930-D936. https://doi.org/10.1093/nar/gkx1024

88. Fong PP, Ford AT (2014) The biological effects of antidepressants on the molluscs and crustaceans: a review. Aquat Toxicol 151:4-13. https://doi. org/10.1016/j.aquatox.2013.12.003

89. OECD (2014) Detailed review paper (DRP) on molluscs life-cycle toxicity testing. Doi: https://doi.org/10.1787/9789264221468-en

90. Thiebault T, Boussafir M, Le Milbeau C (2017) Occurrence and removal efficiency of pharmaceuticals in an urban wastewater treatment plant: Mass balance, fate and consumption assessment. J Environ Chem Eng 5(3):2894-2902. https://doi.org/10.1016/j.jece.2017.05.039

91. Comber S, Gardner M, Sörme P, Leverett D, Ellor B (2018) Active pharmaceutical ingredients entering the aquatic environment from wastewater treatment works: a cause for concern? Sci Total Environ 613-614:538-547. https://doi.org/10.1016/.scitotenv.2017.09.101

92. Nguyen PY, Carvalho G, Reis MAM, Oehmen A (2021) A review of the biotransformations of priority pharmaceuticals in biological wastewater treatment processes. Water Res. https://doi.org/10.1016/j.watres.2020. 116446

93. Dusi E, Rybicki M, Jungmann D (2019) The database Pharmaceuticals in the environment—update and new analysis. In: Umweltbundesamt ed. Chemicals. Dessau-Roßlau

94. Wilkinson JL, Boxall ABA, Kolpin DW (2019) A novel method to characterise levels of pharmaceutical pollution in large-scale aquatic monitoring campaigns. Appl Sci. https://doi.org/10.3390/app9071368

95. Honti M, Bischoff F, Moser A, Stamm C, Baranya S, Fenner K (2018) Relating degradation of pharmaceutical active ingredients in a stream network to degradation in water-sediment simulation tests. Water Resour Res 54(11):9207-9223. https://doi.org/10.1029/2018WR023592

96. White D, Lapworth DJ, Civil W, Williams P (2019) Tracking changes in the occurrence and source of pharmaceuticals within the River Thames, 
UK; from source to sea. Environ Pollut 249:257-266. https://doi.org/10. 1016/j.envpol.2019.03.015

97. Cory WC, Welch AM, Ramirez JN, Rein LC (2019) Naproxen and Its phototransformation products: persistence and ecotoxicity to toad tadpoles (Anaxyrus terrestris), individually and in mixtures. Environ Toxicol Chem 38(9):2008-2019. https://doi.org/10.1002/etc.4514

98. Parezanović GŠ, Lalic-Popovic M, Golocorbin-Kon S, Vasovic V, Milijašević B, Al-Salami H, Mikov M (2019) Environmental transformation of pharmaceutical formulations: a scientific review. Arch Environ Contam Toxicol 77(2):155-161. https://doi.org/10.1007/s00244-019-00630-z

99. Weizel A, Schlüsener MP, Dierkes G, Wick A, Ternes TA (2020) Analysis of the aerobic biodegradation of glucocorticoids: Elucidation of the kinetics and transformation reactions. Water Res. https://doi.org/10.1016/j. watres.2020.115561

100. Shrestha P, Junker T, Fenner K, Hahn S, Honti M, Bakkour R, Diaz C, Hennecke D (2016) Simulation studies to explore biodegradation in watersediment systems: from OECD 308 to OECD 309. Environ Sci Technol 50(13):6856-6864. https://doi.org/10.1021/acs.est.6b01095

101. Cousins IT, Ng CA, Wang Z, Scheringer M (2019) Why is high persistence alone a major cause of concern? Environ Sci Process Impacts 21(5):781-792. https://doi.org/10.1039/c8em00515j

102. Maynard SKC, Lisa A, Joanne Elmoznino, Jutta Hellstern, Birgit Hoeger, Andreas Häner, Reinhard Laenge, Todd Davidson, Michael R Lee, Alison
Nimrod Perkins, Jason R Snape, Joan G Tell (2020) Science-based trigger for the terrestrial assessment of human pharmaceuticals. Paper presented at the SETAC Europe 30th Annual Meeting, Virtual Conference, 03-07 May 2020, Virtual, 03-07 May 2020

103. EU (2000) CVMP/VICH/592/98-FINAL_ - guideline on environmental impact assessment (EIAS) for veterinary medicinal products_-phase I. In. London

104. Schwarz S, Bachmann J, Brückner J, Koch W, Speichert G (2019) Environmental risk assessment of veterinary pharmaceuticals - lessons learned from terrestrial effect data. https://www.umweltbundesamt.de/dokum ent/poster-setac-europa-2019

105. EU (2021) Water reuse. https://ec.europa.eu/environment/water/reuse. htm (2021). Accessed 30 Apr 2021

106. EU (2004) CVMP/NICH/790/03-FINAL-guideline on environmental impact assessment for veterinary medicinal products phase II. In. London

\section{Publisher's Note}

Springer Nature remains neutral with regard to jurisdictional claims in published maps and institutional affiliations.

\section{Submit your manuscript to a SpringerOpen ${ }^{\circ}$ journal and benefit from:}

- Convenient online submission

- Rigorous peer review

- Open access: articles freely available online

- High visibility within the field

- Retaining the copyright to your article

Submit your next manuscript at $\boldsymbol{\nabla}$ springeropen.com 